\title{
Integração produtiva e acordos comerciais: o caso dos países da Aladi *
}

\author{
Karla Sarmento Gonçalves de Souza** \\ Marta Reis Castilho ****
}

\section{Resumo}

O processo de fragmentação da produção tem imprimido novas formas de organização da produção e de comércio entre os países. Dentre os diversos fatores explicativos dessa reorganização das atividades produtivas, aqueles relativos aos custos de comércio são de particular importância. Nesse sentido, os acordos comerciais podem ter uma influência relevante na formação de redes produtivas regionais e, mesmo, globais. Este artigo busca investigar se os acordos firmados no âmbito da Aladi contribuíram para aprofundar a integração produtiva na região, por meio da análise do perfil do comércio regional e da estimação de um modelo gravitacional. O grau de integração dos países da região nas redes produtivas internacionais e regionais é bem inferior aquele observado na Ásia, na América do Norte e na Europa. No entanto, as estimações sugerem que os acordos da Aladi exerceram uma influência fraca, porém, positiva sobre os fluxos regionais de partes, componentes e bens de capital.

Palavras-chave: Integração comercial; Integração produtiva; Aladi; Associação Latino-Americana de Integração; Modelo gravitacional; Estágios produtivos.

\section{Abstract \\ Productive integration and trade agreements: an analysis of Latin American Integration Association (LAIA) countries}

The process of fragmentation has led to a global reorganization of production and has conditioned, to a large extent, the insertion of countries into international trade flows. Among the factors explaining this reorganization of productive activities, those relating to transportation costs and trade barriers are of particular importance. In this context, trade agreements can play a significant role in the formation of regional production networks. This paper investigates whether the trade agreements signed under LAIA have contributed to deepening the regional integration of production. In order to do this, we analyze the trade composition by stages of production and estimate an extended version of a gravity model. The results reveal a low degree of integration of LAIA countries in both the international and regional trade of parts, components and capital goods, far below that observed in Asia, North America and Europe. Even so, LAIA agreements seem to have produced a somewhat positive influence on regional flows.

Keywords: Trade integration; Productive integration; LAIA; Gravity model; Productive stages.

\section{JEL F15.}

* Artigo recebido em 8 de setembro de 2013 e aprovado em 8 de janeiro de 2016. Parte desse trabalho foi desenvolvido no âmbito do Prêmio Jovem Economista da Rede Mercosul - 2012.

${ }^{* *}$ Doutora em Economia pela Universidade Federal Fluminense (UFF), Niterói, RJ, Brasil. E-mail: karla_sgs@yahoo.com.br.

${ }^{* * *}$ Professora Associada do Instituto de Economia da Universidade Federal do Rio de Janeiro (트/UFRJ), Rio de Janeiro, RJ, Brasil. E-mail: castilho@ie.ufrj.br. 


\section{Introdução}

A história recente da América Latina é marcada por diversas tentativas de aprofundar os laços entre os vizinhos por meio de acordos preferenciais de comércio. A mais ambiciosa delas ocorreu na década de 1960 quando, inspirados pelas ideias cepalinas, foi fundada a ALALC (Associação Latina Americana de Livre Comércio). Desde 1980, essa foi substituída pela Aladi (Associação Latino Americana de Integração), que consiste em uma rede de acordos bilaterais e multilaterais de comércio.

É dentro desse arcabouço institucional que a relação comercial entre os países da região vem se aprofundando nos últimos 30 anos. Em 1980, a participação da Aladi na corrente de comércio da região era de 13\%. Desde 2010, a participação da Aladi tem se mantido em 15\%, após ter atingido 17\% em 1995. O acordo prevê diversos mecanismos de incentivos ao comércio, sendo as preferências tarifárias o principal deles (Paiva; Braga, 2007). Atualmente, observa-se uma margem de preferência média de relativamente $70 \%$ à média da tarifa Nação Mais Favorecida ${ }^{1}$.

Apesar de o comércio regional ter crescido e ser de particular importância para determinados países e setores, um dos principais objetivos das primeiras iniciativas de integração latino-americana - a utilização da integração comercial como meio de incentivar o desenvolvimento produtivo (em particular, industrial) da região - pouco avançou. Ao longo dos mais de 50 anos das iniciativas de integração na América Latina, o caráter 'comercialista' dos acordos de integração prevaleceu sobre o 'industrialista'. De acordo com Chudnovsky e Campbell (1991), o caráter industrialista predominaria quando prevalecesse a preocupação com a integração dos parques produtivos nacionais. Nesse caso, os acordos estariam promovendo o que Hamaguchi (2010) chama de integração produtiva regional. Na América Latina, essa discussão esteve presente quando da criação da ALALC nos anos 60 e, mais tarde, ainda que de forma tímida, quando da criação do Mercosul.

Recentemente, o tema da integração produtiva ganhou importância no cenário internacional devido às transformações econômicas recentes associadas ao processo de fragmentação da produção e à consequente formação de redes regionais e globais de produção e comércio. O processo de fragmentação - ou de segmentação - da produção, ao partilhar o processo produtivo e reorganizar a produção em diferentes países, provocou, a partir de meados dos anos 90, um aumento expressivo dos fluxos comerciais mundiais de bens e serviços e, em particular, dos fluxos de partes e componentes (ou bens intermediários). De acordo com a literatura de comércio internacional, a produção dos bens finais vem sendo fragmentada de acordo com as vantagens comparativas de cada país e o processo produtivo, composto por etapas com diferentes requerimentos tecnológicos e de fatores,

(1) Para mais detalhes sobre a estrutura tarifária da região ver Souza (2015). 
dividido de acordo com a eficiência relativa de cada país envolvido no processo (Hamaguchi, 2010; Sturgeon, 2013; Cepal, 2013).

Dos diversos fatores explicativos dessa reorganização das atividades produtivas, aqueles relacionados aos custos de transação entre as diversas unidades envolvidas no processo de produção ou montagem e de comercialização de um bem são de particular importância. Jones e Kierkowski (1990) se referem a esses custos como "service link costs" (custo de conexão de serviços), que surgem devido à separação física da produção e consistem em custos de transporte, barreiras comerciais e de coordenação das atividades.

Dada a relevância dos custos de comercialização, os acordos preferenciais de comércio são um elemento estimulador da articulação das atividades que compõem o processo de produção fragmentado. Ou seja, a integração regional ganha uma dimensão 'produtiva' na medida em que acordos preferenciais podem favorecer a distribuição de etapas produtivas entre os parceiros comerciais regionais, gerando potenciais benefícios para todas as economias envolvidas (Hamaguchi, 2010; Machado, 2010). Essa constatação nos remete, de alguma forma, à visão cepalina de integração dos anos 60, que via na integração regional uma forma de incentivar o desenvolvimento da indústria na região. Ainda que não se pensasse na integração como forma de articular diversas etapas do processo produtivo, a integração regional já era vista como uma forma de viabilizar e/ou complementar os sistemas produtivos nacionais.

Como mostram diversos estudos ${ }^{2}$, os países da América do Sul estão à margem das redes de comércio e produção que se formaram na Ásia, América do Norte e Europa. Porém, existe algum grau de articulação produtiva entre esses países - a utilização do termo "articulação" nesse contexto é proposital - com algumas diferenças setoriais e geográficas relevantes. No presente artigo, analisa-se o grau e o perfil de articulação produtiva entre os países membros da Aladi. De fato, ver-seá que os países da Associação se encontram, com exceção do México, distantes das chamadas cadeias globais de valor, mas que, nas relações intrarregionais, existe um pequeno grau de articulação. Pretende-se com tal análise investigar se a existência dos acordos comerciais da Aladi exerceu algum papel indutor da integração produtiva na região.

Para tal, são utilizados indicadores de comércio que evidenciam a importância dos fluxos de comércio de partes, componentes e bens de capital, que consistem na única ferramenta de análise disponível para o conjunto de países da Aladi. A inexistência e/ou defasagem de Matrizes de Insumo Produto para os países da região inviabiliza a análise da integração produtiva na região com esse tipo de dados. Os fluxos de comércio são classificados por estágio produtivo, que distingue

(2) Para uma análise mais detalhada, ver Cepal (2013); Baumann (2010) e Motta Veiga e Rios (2008). 
partes, componentes e bens de capital, fornecendo uma medida de integração produtiva ao longo da última década abrangendo todos os países da Aladi. Em seguida, avalia-se em que medida os acordos comerciais na região têm contribuído para sua evolução a partir da estimação do modelo gravitacional. Essa ferramenta é tradicionalmente utilizada para avaliar os determinantes dos fluxos bilaterais de comércio, dentre eles a existência de acordos preferenciais de comércio (APC). No presente artigo, como se pretende examinar se os acordos contribuem para a integração produtiva na região, o modelo será estimado para os fluxos de comércio desagregados por estágio de produção. Essa avaliação integra adicionalmente um elemento que nos parece relevante para a análise do tipo de inserção da América Latina nas cadeias globais de valor - a especialização desses países fortemente baseada em setores intensivos em recursos naturais.

O presente trabalho está organizado em 5 partes. Após essa introdução, a primeira seção apresenta uma breve revisão da literatura que trata da questão da integração produtiva. A segunda seção contém uma caracterização dos fluxos de comércio da região. Na terceira seção, é estimado o modelo gravitacional. Por fim, as conclusões buscam chamar a atenção para as principais contribuições desta pesquisa para o debate acerca da relação entre acordos comerciais e integração produtiva na América Latina.

\section{A integração produtiva regional em um contexto de fragmentação}

Apesar de amplamente discutida, "a integração produtiva regional (IPR) não é um conceito bem definido nem na literatura acadêmica nem tampouco na literatura de negócios" (Hamaguchi, 2010, p. 311). Existe uma ambiguidade na literatura acerca do conceito de integração produtiva, que pode ser empregado em dois sentidos: um primeiro conceito, oriundo da economia industrial, diz respeito à verticalização ou integração das diversas etapas do processo produtivo, e o outro integração produtiva regional - que trata do fenômeno da articulação produtiva de países envolvidos em acordos preferenciais de comércio. Ainda que, a princípio, sejam tratados de forma distinta, os dois estão relacionados, na medida em que os acordos preferenciais firmados entre os países são capazes de reduzir os custos de comercialização.

O fenômeno da integração produtiva está associado ao processo de fragmentação da produção e está fundamentado na literatura do comércio internacional. A produção de um bem final seria fragmentada de acordo com as vantagens comparativas associadas à dotação de fatores e/ou às capacidades tecnológicas de cada país e o processo produtivo seria composto por etapas produtivas com diferentes intensidades tecnológicas, cuja localização estaria associada à eficiência relativa de cada país envolvido (Hamaguchi, 2010). 
A fragmentação dos processos produtivos depende de diferentes fatores e a questão tecnológica é fundamental. Alguns processos produtivos são passíveis de serem partilhados e outros, não, como é o caso de setores com processos contínuos de produção $^{3}$. Dependendo dos custos de comercialização entre os parceiros, a fragmentação fica circunscrita ao âmbito nacional. Medeiros (2010) destaca a importância da revolução ocorrida na tecnologia da informação, que possibilitou a codificação e a modularização do processo produtivo (física e geograficamente) facilitando a coordenação do processo. Helpman (2010) destaca que estas novas possibilidades tecnológicas de fragmentar a produção levaram as empresas a adotar novas formas de organização e práticas de gestão.

No caso dos setores passíveis de se fragmentar, a distribuição das diferentes etapas produtivas em diferentes países depende, segundo Jones e Kierkowski (1990) da possibilidade de redução dos custos de "conexão dos serviços", ou seja, dos custos de produção e coordenação das atividades. Para que haja fragmentação do processo produtivo, o custo de conexão de serviços que dizem respeito à separação física da produção não pode ser muito alto. No caso da fragmentação internacional, esses custos estão associados aos custos de transporte, barreiras comerciais e à coordenação de atividades envolvendo ambientes culturais e econômicos diferentes.

Kimura e Ando (2005) chamam a atenção para a dimensão geográfica e para a questão da controlabilidade dos custos de conexão de serviços. Segundo estes autores, longas distâncias geográficas ${ }^{4}$ encarecem o produto final, uma vez que aumentam os custos com transporte e exigem mais investimentos em infraestrutura capaz de escoar a produção. Contudo, à medida que se aumenta o volume produzido, as vantagens de localização atuam e fazem com que o processo de produção fragmentado torne-se mais rentável. Dentre as vantagens de localização, os autores destacam, além da própria questão geográfica, outros fatores econômicos, como nível salarial ${ }^{5}$, disponibilidade e capacidade de transferência de recursos e tecnologia e escala de produção. Os custos de conexão dos serviços também são influenciados

(3) Enquanto processos como têxtil, vestuário e eletrônico são passíveis de serem partilhados e ainda são facilmente transportáveis, setores como papel ou petroquímica não têm a possibilidade de ter o processo fragmentado.

(4) Hamaguchi (2010) também afirma que a localização geográfica dos parceiros é uma questão controversa. Se por um lado, grandes distâncias aumentam os custos de transporte e comunicação entre os países, por outro, países vizinhos podem apresentar estruturas produtivas muito semelhantes, devido à disponibilidade de recursos similares, o que reduziria os efeitos positivos da integração produtiva.

(5) Motta Veiga e Rios (2008) apontam o diferencial de custo da mão de obra entre os países desenvolvidos e em desenvolvimento como uma das principais motivadores do processo de fragmentação produtiva em torno do globo. Kimura, Takahashi e Hayakawak (2007) aprofundam a análise sobre a importância das vantagens de localização para que haja redução nos custos de produção e incorporam à análise o papel dos salários relativamente baixos, boa infraestrututra, existência de aglomeração industrial e ambiente político favorável.

Economia e Sociedade, Campinas, v. 25, n. 1 (56), p. 173-207, abr. 2016. 
pela controlabilidade do processo, especialmente no que diz respeito à credibilidade, à informação incompleta e à existência de um sistema de solução de controvérsias ${ }^{6}$.

As EMN tiveram - e ainda têm - um papel proeminente na expansão desse processo de fragmentação internacional. Sua capacidade financeira e experiência gerencial internacional fizeram com que estas empresas pudessem implementar estratégias de exploração das vantagens comparativas em diferentes etapas do processo produtivo. Isso se deu via investimento direto estrangeiro ${ }^{7}$ ou via subcontratação internacional. De acordo com Macadar (2010), tais estratégias permitiriam às EMN se especializarem em suas competências e transferir parte de sua atividade produtiva para um país que apresentasse custos mais baixos em outras etapas do processo produtivo.

Outra característica que vem sendo observada no cenário internacional é a profusão de acordos regionais, muitos deles indo além das disciplinas comerciais. São os chamados acordos "profundos" que, em geral, incluem cláusulas referentes a investimento, que facilitam, em geral, as estratégias de internacionalização acima descritas.

A integração produtiva regional tratada nesse artigo corresponde ao processo de fragmentação da produção entre países que pertencem a acordos preferenciais. Dullien (2010) define integração produtiva regional como um processo de verticalização do processo produtivo, em que os estágios da produção seriam divididos entre vários países. $\mathrm{O}$ autor sustenta que a integração produtiva baseada em acordos preferenciais é um instrumento eficaz para promover o desenvolvimento equitativo das economias em uma determinada região. Esta prática pode "contribuir para o progresso tecnológico e o desenvolvimento da capacidade produtiva da economia em questão" (Dullien, 2010, p. 143). Dessa forma, não há oposição entre integração produtiva e integração comercial: afirmando que a última pode, dependendo de sua configuração, contribuir para a primeira. Ainda que não seja suficiente para que ocorra. Para a discussão sobre a integração produtiva regional na América Latina os conceitos são complementares e devem se dar de forma concomitante.

Embora grande parte da literatura sobre integração produtiva regional date da década de 90 , o conceito é anterior à ela. Tal noção aparece nas análises da

(6) Para uma análise mais detalhada ver Jones e Kierkowski (1990).

(7) Segundo Miroudot e Ragoussis (2009) e Helpman (2011) os IDEs podem ser tradicionalmente definidos como vertical (quando uma parte do processo produtivo é transferido para outro país que detenha vantagens produtivas naquela etapa) e horizontal (quando o processo produtivo é integralmente replicado no país hospedeiro). As EMN ainda podem adotar a estratégia de Plataforma de Exportação (a filial reproduz todo o processo produtivo da matriz no mercado doméstico e exporta para outros países próximos geograficamente), cujo principal objetivo é reduzir custos de transporte. Porém, a distinção entre os diversos tipos de IDE vem sendo cada vez mais tênue, sendo crescentemente observadas "estratégias de integrações complexas". 
corrente Cepalina, que apresenta uma reflexão própria para a questão do desenvolvimento dos países da América Latina. Esta escola associa o processo de integração produtiva ao desenvolvimento econômico, visto que a integração seria um elemento importante para a industrialização das economias subdesenvolvidas. A integração econômica apoiaria a industrialização ao gerar um mercado regional que daria escala para economias pequenas (caso de diversos países latino-americanos), possibilitaria ganhos de eficiência associados à competição entre as firmas regionais e consistiria ainda em um aprendizado para os países poderem posteriormente exportar para os países centrais. A associação entre integração comercial e desenvolvimento produtivo esteve presente na concepção e desenvolvimento da ALALC nos anos 60, porém, não está presente na formação da Aladi, devido ao caráter menos aprofundado da integração que permeia essa última iniciativa ${ }^{8} . \mathrm{Na}$ década de 1990, o processo de Substituição de Importação já havia se esgotado, a Cepal propõe a adoção de uma estratégia batizada de "transformação produtiva com equidade", enfatizando o aumento da competitividade e a inserção internacional da região (Cepal, 1994).

O tema da integração produtiva ressurgiu no âmbito do acordo do Mercosul, em meio à discussão sobre o tipo de integração perseguida, em que se confrontavam as concepções 'comercialista' e 'industrialista'. Chudnovsky e Campbell (1991) argumentam que, na visão comercialista, a eficiência do processo de integração aparece como resultado de um processo de liberalização, que conduz a uma especialização do tipo intersetorial baseada nas vantagens comparativas estáticas. Já para a vertente industrialista, a integração deveria ser ampla e servir para reforçar a indústria regional face à competição do resto do mundo. O governo atuaria no sentido de orientar a atividade produtiva com o intuito de promover o aprofundamento do processo industrial.

De forma geral, na medida em que os custos associados ao comércio ganham importância devido ao maior volume de comércio, a criação de acordos comerciais facilitaria - ou até estimularia - a instalação de cadeias de valor em um espaço integrado economicamente (Hamaguchi, 2010; Machado, 2010). A integração regional poderia gerar uma reorganização da produção, conduzindo a uma alocação

(8) O perfil tarifário vigente na Aladi não revela nenhuma prioridade à integração produtiva na região no sentido aqui utilizado. Ou seja, as tarifas aplicadas segundo o estágio de produção não apresentam sistematicamente reduções mais acentuadas para bens intermediários e bens de capital. Para maiores detalhes, ver as tarifas aplicadas no interior da Aladi por estágio de produção em Souza (2015).

(9) Nesta etapa, a integração econômica seria capaz de gerar resultados positivos do ponto de vista produtivo (aumento da eficiência produtiva e da difusão tecnológica, melhora nas expectativas dos agentes, captador de investimentos externos). Nesta fase de integração regional como etapa para uma integração internacional mais ampla, os países buscariam transformar suas indústrias de forma a torná-las mais eficientes e, para isto, seria necessária a adoção de componentes novos nas relações entre os países, como a implantação de estratégias empresariais de âmbito regional (Braga, 2001; Cepal, 1994). 
mais eficiente dos recursos disponíveis. Dentre as vantagens da integração produtiva no âmbito de economias integradas via acordos comerciais preferenciais, podemos destacar a possibilidade de criação ${ }^{10}$ de comércio no sentido vineriano. Estes acordos também proporcionam efeitos dinâmicos, tais como ganhos de escala associados à ampliação do mercado, ganhos de aprendizado promovido pelas novas relações produtivas estabelecidas com os parceiros, estímulo à pesquisa e desenvolvimento, minimização das distorções no consumo, aumento dos fluxos de IDE, assim como outras vantagens não tradicionais.

Kosacoff e López (2008) argumentam que esses acordos também proporcionam a integração dos países nas cadeias globais de valor, ademais podem fazer parte de uma estratégia de "catching-up" para as economias que ficaram a margem na evolução do processo produtivo. Ao nível da firma, pode servir de aprendizado e melhorar sua competitividade. Em particular, no caso de países em desenvolvimento, acredita-se que os acordos preferenciais proporcionariam maior dinamismo a essas economias.

\section{Grau de integração produtiva e estrutura tarifária latino-americana}

A avaliação do grau de integração produtiva dos países pode ser realizada a partir de diferentes metodologias, que podem ser agrupadas em dois conjuntos. O primeiro deles reúne os indicadores calculados a partir de estatísticas oriundas das matrizes de insumo-produto que procuram captar o grau de inter-relação da produção nacional com o exterior levando em conta as transações de bens utilizados ao longo do processo produtivo, sendo pioneiro o índice de especialização vertical proposto por Hummels et al. (1998). Apesar da riqueza das informações contidas nesses indicadores, eles têm, especialmente no caso dos países da América Latina, uma cobertura restrita e baixa comparabilidade, devido à defasagem na divulgação das matrizes de insumo-produto e às diferenças de classificações setoriais.

Outro grupo de indicadores tenta captar o grau de integração produtiva dos países e setores nas redes globais de comércio e produção a partir da estimativa da importância do comércio de bens intermediários de um país. Em função da fragmentação da produção e de sua distribuição em diferentes países, os fluxos internacionais dos bens intermediários indicam em que medida a produção nacional está articulada com fornecedores e compradores internacionais. Tais indicadores diferem entre si no que se refere à escolha das variáveis (exportações, importações, fluxo de comércio e produção) e, sobretudo, quanto à identificação dos bens intermediários, que depende da classificação empregada. Aqui, utiliza-se a tipologia de produtos segundo os estágios de produção proposta Lemoine e Unal-Kesencil

(10) Ainda que em um primeiro momento possa haver algum grau de desvio de comércio, conforme as relações produtivas forem se aprofundando, esta "desvantagem" inicial tende a ser superada. 
(2002), que foi construída a partir da classificação BEC (Broad of Economic Categories) e que distingue os produtos de acordo com seu uso final (intermediário ou final).

A tipologia proposta identifica 5 categorias de produtos: bens primários, bens intermediários semiacabados, bens intermediários de partes e componentes ${ }^{11}$, bens finais de capital e bens finais de consumo. Esta reagregação dos dados permite identificar a importância da parcela de comércio de partes e componentes e bens de capital no comércio total, que evidenciam o grau de integração do país nas redes internacionais de produção.

\subsection{Evolução e perfil comercial}

O comércio intrarregional da Aladi se intensificou de forma significativa desde a sua criação, passando de $13 \%$ do total da corrente de comércio da região em 1980 para 17\% em 1995. Em 2011, a participação da Aladi na corrente de comércio da região foi de $15 \%$.

Os dados desagregados ${ }^{12}$ por estágio de produção para os países da Aladi revelam uma baixa integração desses países nas cadeias globais de valor. Conforme se vê pelo Gráfico 1, do lado das exportações totais da Aladi, as categorias de partes e componentes e as de bens de capital são aquelas que têm menor peso nas exportações totais. Até 2000 , as exportações de bens intermediários semiacabados e de bens finais de consumo eram aquelas com maior participação na pauta exportadora. A partir daí, as exportações de bens primários ganharam participação atingindo $31 \%$ das exportações totais em 2011. Vale dizer que todas as demais categorias perderam com o crescimento das exportações de bens primários, que foram, aliás, fortemente influenciadas pela alta dos preços das commodities. ${ }^{13}$

(11) Esses produtos podem ser descritos como bens intermediários "finalizados", que são, segundo as autoras, "technologically independent but produced in order to be assembled into final goods" (Lemoine; UnalKesenci, 2002, p. 26).

(12) Os dados aqui utilizados são provenientes da base Comtrade e compreende o período entre 1995 a 2011.

(13) A análise dos dados das exportações mundiais, segundo a classificação por estágios de produção, mostra um ganho de participação das exportações de bens primários e de bens intermediários semiacabados nas exportações mundiais superior ao observado e descrito aqui para os países da Aladi. Embora essa informação não forneça uma medida precisa do efeito do aumento dos preços das commodities sobre o valor do comércio, ele revela que a tendência observada para a América Latina refletiu em grande parte o movimento ocorrido em todo o mundo. 
Gráfico 1

Composição das exportações e importações totais da Aladi segundo os Estágios de Produção, 1995-2011 (em \% do total)

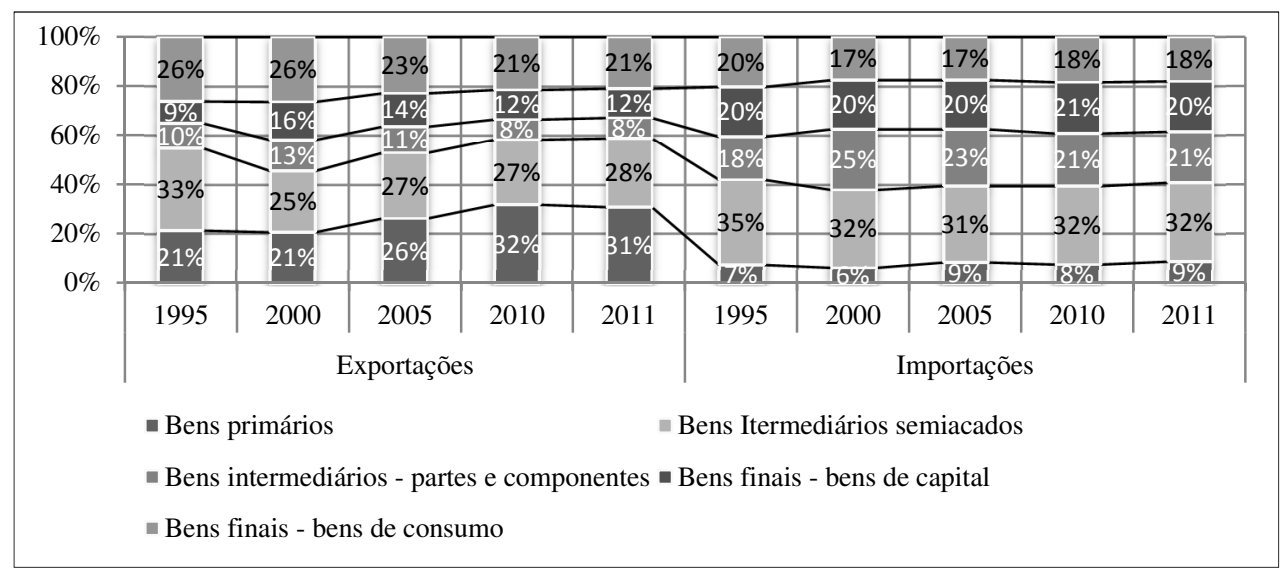

Fonte: Comtrade. Elaboração própria.

As exportações de bens intermediários de partes e componentes em 1995 representavam $10 \%$ da pauta, chegando a $13 \%$ em 2000 , mas desde então vêm perdendo participação (em 2011, representam apenas $8 \%$ do total). Bens finais de capital apresentaram trajetória similar: sua participação aumentou até $2000(16 \%)$ e desde então, seu peso na pauta diminuiu (atingindo $12 \%$ em 2011).

Com relação às importações, o peso de bens intermediários de partes e componentes juntamente com bens de capital é o dobro daquele observado nas exportações. Tal estrutura de comércio desses bens sugere que a inserção dos países da região se dá nos extremos das cadeias produtivas - seja como fornecedores de matérias-primas ou como montadores de bens finais.

A comparação com a composição do comércio mundial coloca em evidencia a baixa integração das economias latino-americanas. O peso de partes, componentes e bens de capital no comércio total em 2011 foi de $30,3 \%{ }^{14}$, percentual bem superior ao percentual observado nas exportações da Aladi e bem inferior àquele observado nas importações.

O perfil do comércio intrarregional dos países da Aladi difere do perfil do comércio extrarregional: no comércio regional, os bens primários têm menor importância e, em compensação, os bens intermediários semiacabados e bens de

(14) Dados de importações mundiais do Comtrade, segundo a mesma classificação utilizada nas demais tabelas. 
consumo final são mais relevantes do que nas exportações totais (ver Gráfico 2) ${ }^{15}$. No que se refere a partes, componentes e bens de capital, seu peso no comércio intrarregional é ligeiramente superior ao peso observado nas exportações totais e, por consequência, bem inferior ao observado nas importações extrarregionais.

\section{Gráfico 2}

Composição das importações intra-Aladi segundo os Estágios de Produção, 1995-2011 (em \% do total)

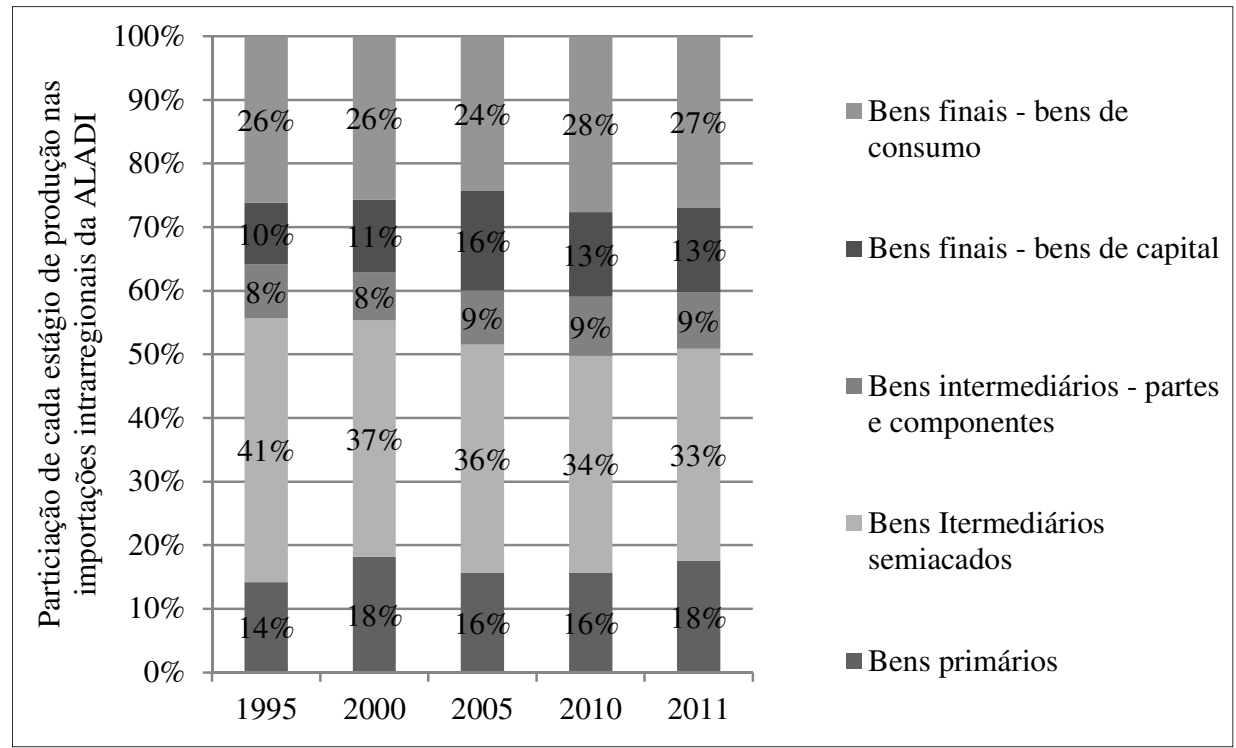

Fonte: Comtrade. Elaboração própria.

A análise do destino das exportações de bens intermediários de partes e componentes e bens finais de capital da Aladi (Gráfico 3) ${ }^{16}$ revela que, com algumas exceções, o padrão de comércio se manteve constante entre 1995 e 2011. Estados Unidos e Argentina são aqueles países onde as exportações desses produtos representam maior parcela, permanecendo como principais destinos ao longo do período. Já México e Colômbia apresentaram um aumento significativo de importância, passando a responder em 2011 por $32 \%$ e $27 \%$ das exportações da Aladi. UE e Ásia, apesar do crescimento do primeiro, são destinos minoritários (10\% e 5\%, quando incluída a China) das exportações latino-americanas de partes, componentes e bens de capital.

(15) Apresentamos apenas as estatísticas de importações, pois teoricamente a estrutura de importações e exportações intrarregionais deveria ser a mesma.

(16) A análise a seguir utiliza a seguinte metodologia: Comércio de bens intermediários de partes e componentes + bens finais de capital Comércio total 
Gráfico 3

Participação das exportações de bens intermediários de partes, componentes e de capital da Aladi em suas exportações totais de bens, segundo destino

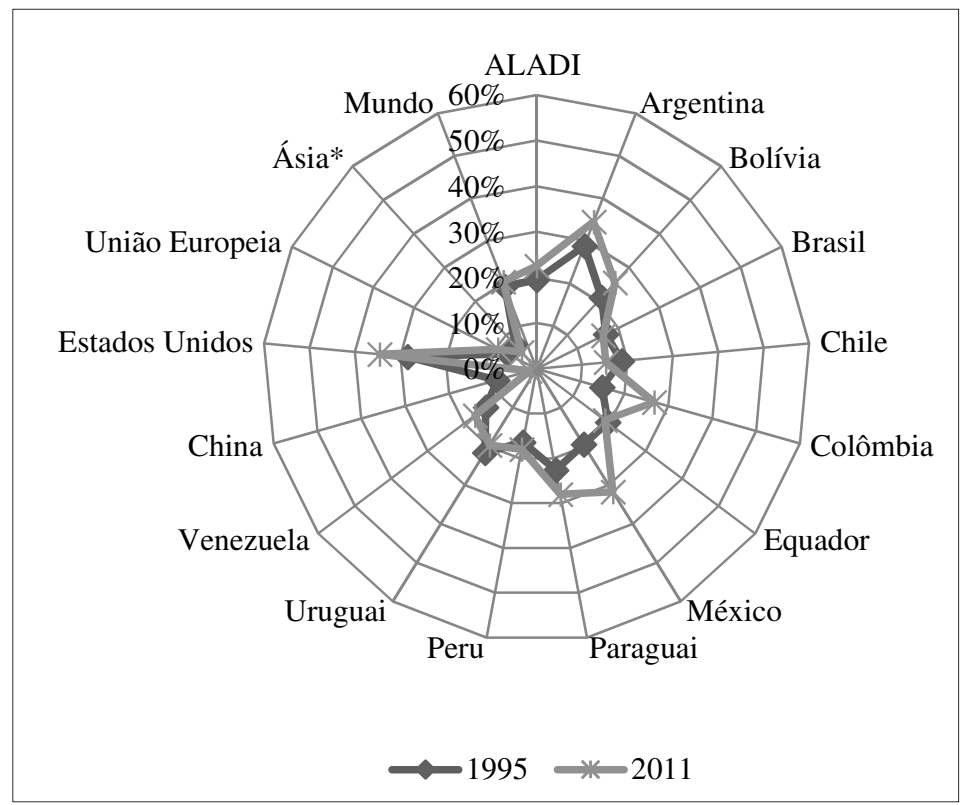

Fonte: Comtrade. Elaboração própria.

Gráfico 4

Participação das importações de bens intermediários de partes e componentes e de capital nas exportações totais da Aladi por origem

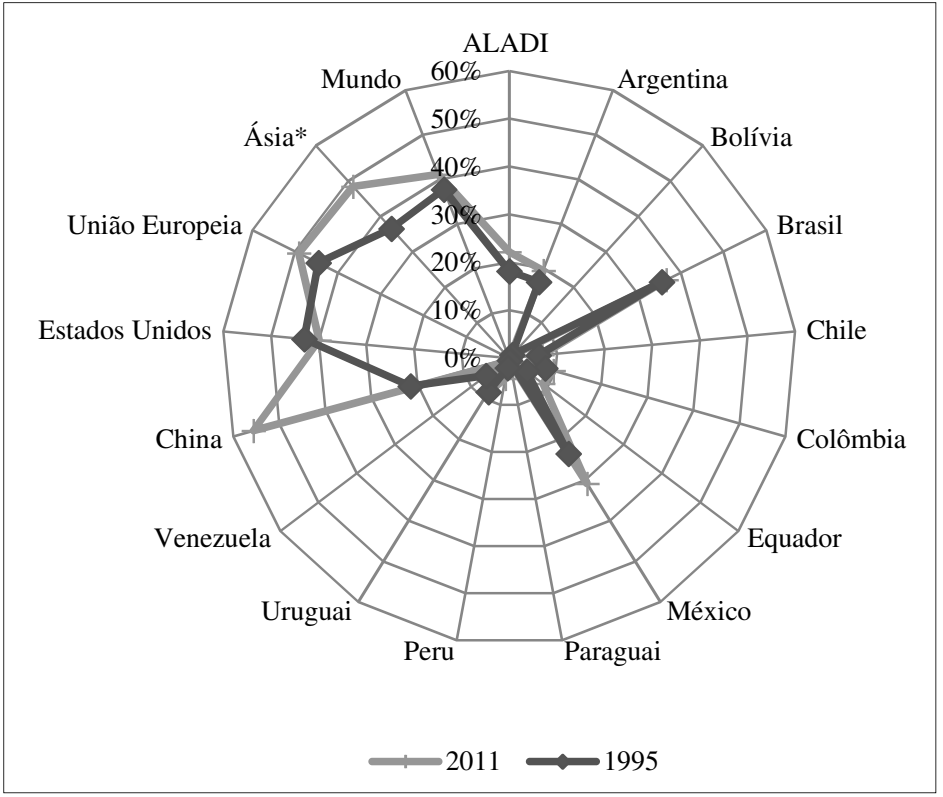

Fonte: Comtrade. Elaboração própria. 
O perfil geográfico das importações de bens de capital, partes e componentes é bem diferente daquele das exportações. Por um lado, os parceiros cuja participação desses produtos é mais elevada (superior a 45\%) são externos à região - UE, EUA, Ásia e China. Por outro lado, o peso desses produtos cresceu fortemente no caso das importações provenientes da Ásia e da China. Dentre os países da Aladi, as importações provenientes do Brasil e do México são aquelas cujo percentual de partes, componentes e bens de capital é mais elevado (37\% e $31 \%$ respectivamente em 2011), destoando do peso desses bens nos demais países da região.

A comparação da estrutura de importações e de exportações dos países da região sugere que, mais do que uma baixa integração nas cadeias globais de valor, a região se insere no cenário internacional como ofertante de bens primários e semifinais ou então de bens finais com forte participação de peças, componentes e bens de capitais provenientes majoritariamente de outras regiões do globo (proeminentemente, a Ásia). O caráter "montador" das indústrias locais é evidente no caso mexicano por conta das maquiladoras. Em outros países da região, como Brasil e Argentina, embora não possa se afirmar que a produção seja majoritariamente montadora a partir de peças e componentes extrarregionais, é fato que o déficit comercial de partes, componentes e bens de capital é significativo e esses países obtêm superávits para bens finais de consumo ${ }^{17}$. Nesse sentido, a Cepal (2013) chega a afirmar que a integração produtiva na América Latina carece de dinamismo e está limitada a indústrias maquiladoras, especialmente no México e na América Central.

\section{Em que medida os acordos preferenciais da Aladi estimulam integração produtiva? Uma estimativa a partir do modelo gravitacional.}

O modelo gravitacional aqui utilizado para avaliar o impacto dos acordos da Aladi sobre os fluxos de comércio de partes, componentes e bens de capital é uma ferramenta utilizada correntemente para a avaliação dos efeitos de acordos comerciais. Ele surgiu no início dos anos 1960, inspirado na lei da Gravitação Universal de Newton, como um método para explicar o fluxo comercial entre dois países. Em sua versão mais simples, o tamanho do país aparece como força de atração e o custo de transporte como fator de repulsão para o comércio entre os parceiros.

(17) Em 2013, segundo os dados do Comtrade, o déficit comercial da Aladi foi de US\$ 66 bilhões para partes e componentes e de US\$ 75 bilhões para bens de capital, enquanto o superávit da região alcançou US\$ 75 bilhões para bens de consumo finais. Esses resultados refletem a situação (semelhante) de México, Brasil e Argentina - ambos apresentaram déficits para partes, componentes e bens de capital e superávit para bens finais. Ademais, os déficits de partes, componentes e bens de capital desses três países com a Ásia são bastante representativos (no caso do México, por exemplo, o déficit relativamente à China corresponde ao dobro do déficit total desses produtos). 
Em sua versão tradicional, o modelo gravitacional utiliza a renda como proxy para o tamanho das economias envolvidas e a distância geográfica para os custos de transportes. A estas variáveis, são acrescentadas outras que compõem os custos de transação entre os países e que são passíveis de explicar os fluxos comerciais, tais como a existência de relações coloniais no passado ou de fronteira e idioma comum. O modelo normalmente é estimado sob a forma logarítmica, os resultados correspondendo diretamente às elasticidades dos fluxos de comércio relativamente a cada variável ${ }^{18}$.

A preocupação com a fundamentação teórica do modelo surgiu somente após algumas décadas de uso. O primeiro autor a se preocupar com esta questão foi Linnemann (1966), ao propor a inclusão de outras variáveis suscetíveis de explicar o comércio entre dois países, derivando a equação gravitacional de um modelo de Equilíbrio Geral Walrasiano. Posteriormente, Anderson (1979) desenvolveu uma formulação teórica para a equação, baseando-se em modelos de equilíbrio geral com preferências com elasticidade de substituição constante e bens diferenciados por país. Deardoff (1995) mostrou que a equação gravitacional também podia ser derivada a partir de modelos de concorrência perfeita do tipo Hercksher-Ohlin, assim como de modelos de concorrência monopolística e de produtos diferenciados segundo a origem. ${ }^{19}$ Testes empíricos realizados por Evenett e Keller (2002) reforçaram a múltipla paternidade teórica da equação gravitacional, que pode ser derivada tanto de modelo Hercksher-Ohlin quanto de modelos de concorrência imperfeita (monopolística). Desta forma, a contribuição mais relevante desta discussão foi corroborar que as relações, antes intuitivas entre o volume transacionado com a renda e distância entre os países, foram deduzidas a partir de modelos tradicionais de comércio internacional.

Com frequência, o modelo gravitacional foi utilizado para avaliar os efeitos de acordos comerciais. A fim de captar tal efeito, dois procedimentos são possíveis. O mais usual é por meio da introdução de dummies que representam os acordos comerciais. A alternativa é introduzir medidas diretas de proteção (tarifas, por exemplo) que representam as diferenças decorrentes das concessões preferenciais (Castilho, 2001). Como normalmente as estimações são feitas em níveis de agregação elevados, médias tarifárias ou outras estatísticas acabam perdendo seu poder explicativo. Ademais, é difícil obter-se uma série longa e abrangente em termos de países.

(18) Na forma log-linear os resultados obtidos pela estimação já nos fornecem as elasticidades de cada variável.

(19) Evenett e Keller (2002) reforçaram, com testes empíricos diversos, a múltipla "paternidade teórica" da equação gravitacional. 
O modelo gravitacional pode ser estimado para fluxos bilaterais de produtos ou grupo de produtos ou ainda para avaliar os determinantes do comércio intra indústria. Aqui, utilizamos esse modelo para avaliar em que medida os acordos comerciais influenciam os fluxos de comércio definidos segundo os estágios de produção a fim de examinar se a influência deles é mais forte sobre os fluxos de partes, componentes e bens de capital.

\subsection{Equação estimada}

Inspirada no trabalho de Anderson e Van Wincoop (2003) ${ }^{20}$, estimamos aqui uma equação gravitacional ampliada, conforme explicitado abaixo:

$$
\begin{aligned}
& \ln \text { EXPEP }_{i j E P}^{t}=\alpha_{1}+\beta_{1} \ln \text { dist }_{i j}+\beta_{2} \ln Y_{i}^{t}+\beta_{3} \ln Y_{j}^{t}+\beta_{4} \ln \left|y_{i}^{t}-y_{j}^{t}\right|+\beta_{5} l_{i n}^{t}+ \\
& +\beta_{6} \text { Comlang_off }_{i j}+\beta_{7} \text { Colonia }_{i j}+\beta_{8} \text { Contig }_{i j}+\sum_{l} \beta_{9} A_{i j}+\varepsilon_{i j}
\end{aligned}
$$

onde: $\boldsymbol{i}$ representa o país importador e $\boldsymbol{j}$, o país exportador, $\boldsymbol{t}$ corresponde ao ano e $\boldsymbol{E P}$ cada uma das cinco categorias de produtos; $\boldsymbol{E x p E P}$ corresponde às exportações classificadas por estágio de produção; dist representa a distância geográfica medida em quilômetros, $\boldsymbol{Y}$ e $\boldsymbol{y}$ representam respectivamente o PIB e o PIB per capita de cada um dos parceiros - proxy para Renda -, $\boldsymbol{R} \boldsymbol{N}$ corresponde à dotação de recursos naturais do país exportador, Comlang_off, colônia e contig são dummies que indicam a existência de língua oficial comum, relação de colônia entre os dois parceiros e contiguidade (fronteira); $\boldsymbol{A}$ é a dummy representativa dos acordos preferenciais.

Relativamente aos modelos usualmente encontrados, a equação aqui apresenta duas particularidades. Em primeiro lugar, a variável de renda per capita, que normalmente aparece separadamente para cada país e que pode ser interpretada como uma proxy da dotação de fatores, aqui aparece no termo em que é introduzida a diferença das rendas per capita ${ }^{21}$. De fato, na literatura sob fragmentação ${ }^{22}$, é usual apontar a diferença de dotações de fatores e, em particular, no preço e qualificação da mão de obra como um dos fatores que estimulam a localização de etapas de um mesmo processo produtivo em diferentes países. Aqui, adotamos procedimento similar à Kimura et al (2007) que utilizam a diferença absoluta entre os PIB per

(20) Os autores concluíram que o comércio bilateral é determinado pelos custos comerciais relativos, ou seja, pelos fatores de resistência multilateral ao comércio.

(21) A variável renda per capita é uma forma equivalente matematicamente à introdução da variável população dos países, ambas podendo representar a dotação de fatores (basicamente, a abundância de mão de obra) (Gómez; Baleix, 2009). Castilho (1999) destaca que os resultados referentes ao PIB per capita podem ser ambíguos, pois diferenças importantes de renda podem estar associadas a fluxos de comércio do tipo interindústria, enquanto pequenas diferenças estimulam o comércio do tipo intraindústria. Assim, os resultados podem diferir segundo a amostra de países e segundo os setores, se a estimação for feita de forma desagregada.

(22) Hamaguchi (2010), por exemplo, chama atenção para esse aspecto, afirmando que no caso asiático as diferenças de níveis de desenvolvimento entre os países da região têm sido fundamentais para explicar a integração produtiva na região. 
capita do exportador e do importador como proxy para o diferencial salarial entre os parceiros, que seria um dos principais determinantes para a decisão de fragmentar a produção.

Em segundo lugar, foi introduzida uma variável que representa a importância dos recursos naturais para cada país. Sua introdução pretende verificar a hipótese de que a abundância de recursos naturais levaria a uma especialização em setores intensivos nesses recursos, setores esses que se caracterizam na maioria das vezes por processos contínuos de produção e cuja vantagem competitiva se encontra na proximidade da fonte de recursos. Por isso, esse seria um dos fatores explicativos para a baixa integração dos países latino-americanos nas cadeias globais de valor (Motta Veiga; Rios, 2008; Perez, 2012). A variável aqui utilizada para representar a dotação de recursos naturais do país exportador foi construída a partir da participação dos bens agrícolas e os bens extrativos mineral no PIB do país exportador. Acredita-se que seu impacto deva ser positivo para as exportações de bens menos elaborados - especialmente para os bens primários - e perca importância à medida que as exportações se tornem mais sofisticada.

O modelo será estimado para dados de exportação classificados por estágio de produção, conforme a tipologia sugerida por Lemoine e Unal-Kesenci (2002). Um coeficiente positivo para a dummy representativa do acordo preferencial de comércio em bens intermediários de partes e componentes e/ou bens finais de capital sugere que o acordo impacta de forma positiva a integração produtiva do bloco comercial.

Das variáveis gravitacionais usualmente introduzidas nos modelos gravitacionais, a renda consiste em um dos principais determinantes dos fluxos de comércio e espera-se um coeficiente positivo para os PIBs dos países importadores e exportadores em função do efeito direto do tamanho do país sobre os fluxos de comércio, ademais pelo fato de que um país maior apresentar uma maior diversificação na gama de produtos transacionados (Azevedo, 2004). Head (2000) explica que o maior nível de comércio entre estes países também é estimulado pela melhor infraestrutura dos portos e aeroportos e pela incidência de tarifas mais baixas, estando esses dois aspectos positivamente correlacionados com maiores níveis de renda. Para as estimações aqui apresentadas utilizamos o PIB constante a fim de expurgar efeitos preços, associados inclusive a variações do câmbio.

A distância funciona como um fator de resistência ao comércio por consistir em uma proxy para custo de transporte, mas também por representar o tempo gasto no transporte de uma determinada mercadoria e a dificuldade na comunicação entre países e pessoas (Head, 2000). Esses aspectos são fundamentais para a decisão das empresas de 'fragmentar' a produção, que segundo Jones e Kierkowski (1990), é 
motivada pela possibilidade de redução dos custos de produção, especialmente aqueles associados aos service link costs (custos de conexão dos serviços).

A dummy contiguidade, que representa fronteira, estaria relacionada às vantagens de localização. Espera-se que esta variável apresente sinal positivo na medida em que países vizinhos apresentem menores custos de transporte. As dummies língua oficial comum e relação de colônia também estariam positivamente relacionadas ao comércio entre os parceiros, países próximos culturalmente tendem a comercializar mais.

Por fim, são adicionadas dummies ${ }^{23}$ que representam a existência de acordos preferenciais de comércio entre os parceiros. ${ }^{24} \mathrm{~A}$ análise do efeito do acordo será baseada no valor do coeficiente associado a cada dummy: um coeficiente positivo indica que os fluxos comerciais intrabloco são superiores à média da amostra, sugerindo que o acordo estaria impactando positivamente o comércio intrabloco.

A base de dados é composta por 67 países ${ }^{25}$, extraída da base de dados Comtrade e compreende as exportações (desagregadas segundo a classificação STIC Rev. 3 e reagregadas segundo os estágios de produção), para o período de 2000 a 2011. Provêm do CEPII os dados de PIB (Produto Interno Bruto) constante, além de informações sobre distância e dummies que indicam a existência de língua comum, colônia e contiguidade. Para a criação das dummies representativas de acordos preferenciais de comércio (APC) foram utilizadas as informações de acordos registrados na OMC (Organização Mundial do Comércio).

\subsection{Estratégia de estimação}

Apesar da forte capacidade explicativa dos modelos gravitacionais e de sua ampla utilização, diversas questões referentes aos métodos de estimação usados persistem.

Em primeiro lugar, sua forma logarítmica pode gerar perda de observações quando ocorrem exportações iguais a zero e a omissão destas variáveis pode levar a resultados enviesados. Para superar esta dificuldade, Reis e Azevedo (2008) apresentam algumas soluções: a primeira delas seria a exclusão ${ }^{26}$ destes valores da

(23) Infelizmente, a estimação de um modelo utilizando as medidas diretas de proteção que poderiam caracterizar com maior precisão o efeito das preferências tarifárias sobre os fluxos de comércio exige a montagem de uma base de dados de tarifas bilaterais que consiste em um trabalho hercúleo. Essa seria uma maneira de aprofundar a análise relativamente ao presente trabalho e a outros que buscam avaliar o efeito dos acordos sobre a integração produtiva ou a formação de redes regionais de produção (ver Orefice; Rocha, 2011, por exemplo).

(24) A lista com a composição dos acordos encontra-se ao final.

(25) A lista dos países encontra-se no apêndice.

(26) Cheng e Howard (2005) optaram por incluir em sua amostra apenas os fluxos bilaterais diferentes de zero. Anderson (2010) argumenta que, quando o fluxo zero é reflexo de decisões de políticas governamentais, excluir os zeros da amostra seria uma decisão aceitável. Alguns autores arbitram um valor - 10\%, no caso de Head (2000) 
amostra. Linders e Groot (2006) argumentam que esta opção é inadequada, principalmente, em se tratando de fluxos de comércio desagregados, em que o fluxo zero revela uma informação importante sobre o padrão de comércio entre os países. Sua desconsideração pode gerar problemas de viés na amostra e de inconsistência para os resultados da equação gravitacional, sobretudo se eles representarem uma parcela significativa dos fluxos. Uma segunda solução, utilizada por diversos autores, inclusive Reis e Azevedo (2008), é substituir estes valores por valores próximos a zero. Entretanto, Gómez (2010) argumenta que manipulações ad hoc fornecem estimativas tendenciosas e ineficientes. Azevedo (2004) afirma que, apesar de alguns métodos parecerem mais adequados, testes realizados pela literatura indicaram que os resultados encontrados por cada um destes métodos tendem a convergir. Uma quarta solução, adotada por Castilho (2001), Azevedo (2004), Linders e Groot (2006) e Jorge e Castilho (2011), é a utilização do Método de Heckman $^{27}$, que trata da correção do viés de seleção resultante da omissão das observações. Esse método integra a probabilidade dos fluxos serem positivos, o que pretende solucionar um possível viés de seleção (ou seja, o fato dos fluxos nulos resultarem da amostra utilizada e, assim, estarem gerando resultados enviesados). Embora Gómez (2010) conclua, em sua comparação entre diversos métodos, que o de Heckman tenha se mostrado o mais eficiente para tratar a questão dos fluxos zeros, ele é muito custoso "computacionalmente" e encontra dificuldades em rodas amostras com muitas dummies. Na presente estimação, para a utilização do Heckman, teríamos que incluir dummies anuais e para pares de países, inviabilizando sua utilização.

O método de Painel em Poisson consiste em outra forma de corrigir os zeros, sem modificações $a d$ hoc na amostra. O método de Poisson pondera as observações e a estimação tomando como base a matriz de estimadores de covariância robusta Eicker-White (Jorge; Castilho, 2011; Gómez; Baleix, 2009). A estimação por Painel em Poisson corrige, então, o problema associado aos zeros sem incorrer no problema indicado por Gómez (2010) de que o modelo Poisson (puro) não dá conta do problema de heterogeneidade não observada dos países. Ao estimar-se a equação em Painel em Poisson, estão sendo controladas as especificidades temporais e relativas aos pares de países (heterogeneidade não observada).

Outro problema recorrente na estimação do modelo gravitacional consiste na ocorrência de heterocedasticidade, que pode gerar estimadores inconsistentes em estimativas por MQO. A base de dados com um grande volume de zeros viola a

- a partir do qual julgam que a não consideração dos fluxos zeros implica em uma perda relevante de informação e, por consequência, enviesa os resultados.

(27) O método de Heckman consiste na estimação do modelo em duas etapas, a primeira é a estimação do modelo por meio do modelo Probit, para que sejam calculadas as probabilidades dos fluxos serem positivos. E, em uma segunda etapa em que se associam as esperanças condicionais calculadas anteriormente via estatística de Mills, para enfim estimar o modelo por MQO (Jorge; Castilho, 2011). 
condição de distribuição normal, uma vez que concentra uma quantidade significativa de pequenos valores e, se a equação for log-linearizada, as propriedades da amostra serão alteradas devido à eliminação dos fluxos nulos. Diversas soluções são encontradas na literatura. Jorge e Castilho (2011) corrigem esse problema ao estimar o modelo em Poisson. Azevedo (2004) optou por tratar o problema estimando a equação por meio do método de mínimos quadrados ponderados, utilizando como ponderador o PIB dos importadores. Já Barcellos (2002) utiliza o método de mínimos quadrados generalizados (MQG), além da correção de White.

E, por fim, um problema comum em modelos do tipo cross-section é a ausência de controle sobre a heterogeneidade entre os países. A solução adotada por Gómez e Baleix (2009) é o uso da técnica de painel, que permite controlar variáveis relevantes ao longo do tempo. Cheng e Howard (2005) argumentam que o uso de efeitos fixos é o método mais capaz de controlar a heterogeneidade, uma vez que este método incorpora na regressão características não observadas dos países. Azevedo (2004) afirma que a estimação de MQO a partir de dados empilhados (pooled data) apresenta algumas vantagens em relação à estimação em cross-section, pois permitiria a introdução de uma dummy capaz de testar a estabilidade dos coeficientes da regressão.

A discussão acerca da especificação da equação gravitacional e dos métodos de estimação parece não encontrar consenso entre os autores que propõem diferentes técnicas econométricas para corrigir os problemas mencionados. Goméz e Baleix (2009) argumentam que todos os métodos até então propostos para estimar o modelo gravitacional apresentam limitações, e, por isso, têm sido prática comum a estimação da mesma base de dados por diversas técnicas nos estudos que utilizam modelo gravitacional. Head e Mayer (2014) vão além, sugerindo ser desejável a estimação por diferentes métodos como forma de testar a robustez dos resultados.

No que diz respeito ao uso dessa ferramenta para avaliação dos fluxos de comércio de partes e componentes, Baldwin e Taglioni (2011) argumentam que a equação padrão apresenta algumas limitações. Dentre elas, os autores argumentam que quando o comércio de bens intermediários torna-se a maior parcela dos bens transacionados, o PIB $^{28}$ deixa de ser uma proxy adequada para oferta e demanda. Uma solução proposta pelos autores nestes casos é a substituição dos PIBs do importador e exportador por efeitos fixos que relacione país e tempo. No caso da

(28) Segundo os autores, o PIB é uma boa proxy da capacidade de demanda e de oferta quando a maior parte dos fluxos de comercio é composto por bens de consumo. Países especializados em etapas intermediárias do processo produtivo não necessariamente mostram correspondência entre tamanho do fluxo comercial de bens intermediários e seu tamanho econômico. 
presente estimação, a estimação de Poisson em Painel ${ }^{29}$ não converge caso haja a introdução de um número tão elevado de dummies.

Estimou-se aqui a equação com um modelo de Painel em Poisson. As estimações de dados em painel permitem controlar tanto para a dimensão temporal, que suaviza possíveis oscilações macroeconômicas ao longo do período em estudo, quanto para as características específicas dos pares de países, que capturam a heterogeneidade existente entre os parceiros (inclusive efeitos de políticas comerciais). Quanto aos fluxos zero, a estimação em Poisson preserva a informação neles contida, sem a necessidade de manipulações ad hoc dos dados. Enfim, o método de Poisson corrige o problema da heterocedasticidade. O Painel em Poisson foi estimado por efeitos aleatórios. A especificação do modelo e o fato da dimensão cross-section consistir nos pares de países inviabilizam a estimação por efeitos fixos. A equação foi estimada para a base completa (para todos os estágios de produção) e por estágio de produção.

\subsection{A influência da Aladi sobre a integração produtiva na região}

A influência da Aladi sobre os fluxos comerciais de seus membros (especialmente sobre os bens intermediários de partes, componentes e bens finais de capital) é avaliada a partir dos coeficientes das dummies que indicam os fluxos intrarregionais dos bens segundo as diversas categorias. Como a amostra abrange um conjunto bastante diverso de países, no caso da Aladi, foram criadas duas dummies distintas a fim de colocar em evidência as diferenças entre os fluxos intra e os extrarregionais: a primeira delas, chamada daladi, se refere aos fluxos intrarregionais, e a segunda, chamada daladi_out, capta as relações dos países da Aladi com o Resto do Mundo ${ }^{30}$.

A Tabela 1 apresenta os resultados para o conjunto de produtos e para as cinco categorias de produtos. Para o conjunto dos produtos, os coeficientes estimados para as variáveis gravitacionais mostram resultados esperados. O coeficiente da variável referente à importância dos recursos naturais denota uma influência positiva para o conjunto das exportações. Quanto aos acordos comerciais, algumas dummies não mostram resultados significativos, indicando que os acordos não tiveram, nos anos 2000, influência relevante sobre o comércio intrarregional este é o caso notadamente do Nafta. A Aladi parece ter uma influência sobre o comércio regional, visto que o coeficiente da dummy para o comércio intrarregional supera o do comércio extrarregional dos países latino-americanos.

(29) Como dito anteriormente, a escolha dessa técnica se dá com o objetivo de corrigir, entre outros, os fluxos nulos. No caso de Baldwin e Taglioni (2011), a questão dos zeros parece ser ignorada.

(30) A dummy daladi out assume valor 1 quando apenas o exportador pertence à Aladi. 
Tabela 1

Estimação (Painel em Poisson) da equação gravitacional para Aladi (variável dependente: exportações)

\begin{tabular}{|c|c|c|c|c|c|c|}
\hline Variáveis & Total & EP1 & EP2 & EP3 & EP4 & EP5 \\
\hline \multirow{2}{*}{ Distância } & $-0.823 * * *$ & $-1.378^{* * *}$ & $-1.112 * * *$ & $-0.208 * * *$ & $-0.531 * * *$ & $-0.884 * * *$ \\
\hline & $(0.027)$ & $(0.058)$ & $(0.031)$ & $(0.044)$ & $(0.035)$ & $(0.028)$ \\
\hline \multirow{2}{*}{ Log (pib_cte_exp) } & $1.084 * * *$ & $1.029 * * *$ & $1.258 * * *$ & $0.801 * * *$ & $1.307 * * *$ & $0.902 * * *$ \\
\hline & $(0.000)$ & $(0.000)$ & $(0.000)$ & $(0.000)$ & $(0.000)$ & $(0.000)$ \\
\hline \multirow{2}{*}{ Log (pib_cte_imp) } & $0.696 * * *$ & $1.716 * * *$ & $0.690 * * *$ & $0.333 * * *$ & $0.309 * * *$ & $0.908 * * *$ \\
\hline & $(0.000)$ & $(0.000)$ & $(0.000)$ & $(0.000)$ & $(0.000)$ & $(0.000)$ \\
\hline \multirow{2}{*}{ Log (gap_pib_cte_capita) } & $0.057 * * *$ & $0.153 * * *$ & $0.039 * * *$ & $0.083 * * *$ & $0.036 * * *$ & $0.052 * * *$ \\
\hline & $(0.000)$ & $(0.000)$ & $(0.000)$ & $(0.000)$ & $(0.000)$ & $(0.000)$ \\
\hline \multirow{2}{*}{ Contiguidade } & $0.927 * * *$ & $1.315 * * *$ & $0.745 * * *$ & $1.047 * * *$ & $0.940 * * *$ & $1.271 * * *$ \\
\hline & $(0.124)$ & $(0.220)$ & $(0.143)$ & $(0.210)$ & $(0.173)$ & $(0.135)$ \\
\hline \multirow[t]{2}{*}{ Colônia } & 0.0435 & $-0.930 * * *$ & 0.117 & $0.385^{*}$ & $0.488 * *$ & 0.199 \\
\hline & $(0.145)$ & $(0.249)$ & $(0.168)$ & $(0.226)$ & $(0.194)$ & $(0.167)$ \\
\hline \multirow{2}{*}{ Língua comum } & $0.853 * * *$ & -0.0909 & $0.699 * * *$ & $1.099 * * *$ & $0.992 * * *$ & $0.730 * * *$ \\
\hline & $(0.103)$ & $(0.192)$ & $(0.126)$ & $(0.142)$ & $(0.127)$ & $(0.125)$ \\
\hline \multirow{2}{*}{ Log (Recursos naturais) } & $0.008 * * *$ & $0.203 * * *$ & $-0.008 * * *$ & $0.079 * * *$ & $-0.001 * * *$ & $-0.094 * * *$ \\
\hline & $(0.000)$ & $(0.000)$ & $(0.000)$ & $(0.000)$ & $(0.000)$ & $(0.000)$ \\
\hline \multirow{2}{*}{ Dummy Aladi } & $0.674 * * *$ & $1.902 * * *$ & $1.144 * * *$ & $-0.779 * * *$ & $-0.945 * * *$ & $0.781 * * *$ \\
\hline & $(0.165)$ & $(0.306)$ & $(0.197)$ & $(0.246)$ & $(0.213)$ & $(0.196)$ \\
\hline \multirow{2}{*}{ Dummy Não Aladi } & $0.275^{* * *}$ & $0.861 * * *$ & $0.949 * * *$ & $-2.281 * * *$ & $-2.240 * * *$ & 0.0518 \\
\hline & $(0.068)$ & $(0.114)$ & $(0.079)$ & $(0.104)$ & $(0.087)$ & $(0.077)$ \\
\hline \multirow{2}{*}{ Dummy Asean } & $1.917 * * *$ & 0.426 & $1.245 * * *$ & $3.018 * * *$ & $2.090 * * *$ & $1.580 * * *$ \\
\hline & $(0.268)$ & $(0.442)$ & $(0.310)$ & $(0.421)$ & $(0.354)$ & $(0.309)$ \\
\hline \multirow{2}{*}{ Dummy Cefta } & $0.448^{*}$ & $-0.962 * *$ & $0.450^{*}$ & 0.163 & 0.214 & $0.663^{* *}$ \\
\hline & $(0.230)$ & $(0.385)$ & $(0.266)$ & $(0.364)$ & $(0.305)$ & $(0.265)$ \\
\hline \multirow{2}{*}{ Dummy Cer } & 1.112 & -0.18 & 0.947 & 0.742 & 1.11 & 1.79 \\
\hline & $(1.030)$ & $(1.699)$ & $(1.192)$ & $(1.610)$ & $(1.357)$ & $(1.192)$ \\
\hline \multirow{2}{*}{ Dummy Cis } & $1.763 * * *$ & $2.190 * * *$ & $1.644 * * *$ & 0.716 & $1.729 * * *$ & $2.234 * * *$ \\
\hline & $(0.327)$ & $(0.548)$ & $(0.379)$ & $(0.524)$ & $(0.436)$ & $(0.376)$ \\
\hline \multirow{2}{*}{ Dummy UE } & $0.258 * * *$ & $-2.125 * * *$ & -0.0172 & $1.149 * * *$ & $0.990 * * *$ & $0.475 * * *$ \\
\hline & $(0.091)$ & $(0.179)$ & $(0.104)$ & $(0.145)$ & $(0.121)$ & $(0.103)$ \\
\hline \multirow{2}{*}{ Dummy Efta } & 0.137 & $-1.844 *$ & 0.874 & -0.846 & 0.0169 & 0.0916 \\
\hline & $(0.593)$ & $(0.977)$ & $(0.686)$ & $(0.928)$ & $(0.781)$ & $(0.685)$ \\
\hline \multirow{2}{*}{ Dummy Nafta } & -0.259 & $-4.086 * * *$ & $-1.463 * *$ & $3.499 * * *$ & $3.274 * * *$ & -0.288 \\
\hline & $(0.598)$ & $(0.976)$ & $(0.691)$ & $(0.946)$ & $(0.797)$ & $(0.689)$ \\
\hline \multirow{2}{*}{ _cons } & $0.742 * * *$ & $-10.21 * * *$ & $-3.494 * * *$ & $-1.714 * * *$ & $-4.685 * * *$ & $-4.218^{* * *}$ \\
\hline & $(0.231)$ & $(0.017)$ & $(0.270)$ & $(0.017)$ & $(0.306)$ & $(0.243)$ \\
\hline Observações & 265320 & 53064 & 53064 & 53064 & 53064 & 53064 \\
\hline $\mathrm{N}^{\circ}$ de pares de país & 4422 & 4422 & 4422 & 4422 & 4422 & 4422 \\
\hline
\end{tabular}


A análise dos coeficientes estimados para as variáveis gravitacionais para os 5 grupos de produtos indica que a sensibilidade das exportações relativamente à distância, ao tamanho das economias, à diferença de renda per capita e ainda as variáveis relativas à língua comum, contingência e passado colonial conjunto são em sua maioria significativos. E apresentam, com poucas exceções, os sinais esperados. Suas magnitudes, no entanto, variam bastante. No que se refere, por exemplo, à distância, os coeficientes sugerem que as exportações de partes, componentes e bens de capital (EP4 e EP5) são menos sensíveis aos custos de transporte do que as demais categorias. Por outro lado, o tamanho do exportador é bastante relevante para as exportações de bens de capital (EP4), porém, menos relevante para as exportações de partes e componentes (EP4). O tamanho do importador é mais relevante para os produtos primários (EP1). Essas informações, juntamente com aquelas referentes à diferença de renda per capita (cujos maiores coeficientes foram encontrados para bens primários e bens de partes e componentes) parecem refletir a geografia do comércio mundial. As exportações de bens de capital (EP4) e de bens intermediários semiacabados (EP2) são mais importantes para os países com maiores rendas, enquanto as importações de bens primários (EP1) são mais sensíveis ao tamanho do país importador. A diferença das rendas per capita, que denotam diferenças de níveis de desenvolvimento, são mais importantes para explicar as exportações de bens primários (EP1) e de partes e componentes (EP3).

No que se refere à importância de recursos naturais (lrn), a importância dos setores intensivos em recursos naturais é logicamente mais relevante na explicação dos fluxos de bens primários (EP1). Dos bens industrializados, os coeficientes se mostraram negativos para 3 das 4 categorias: bens intermediários semiacabados (EP2), bens finais de capital (EP4) e bens finais de consumo (EP5). Já os bens intermediários de partes e componentes (EP3) apresentaram coeficiente positivo, contrário ao esperado, ainda que com valor bem pequeno ${ }^{31}$.

A dummy representativa da Aladi apresenta coeficiente positivo para três dos 5 grupos de produtos: bens primários (EP1), bens intermediários semiacabados (EP2) e bens de consumo (EP5). O coeficiente da dummy Aladi apresentou coeficiente negativo e significativo para partes e componentes (EP3) e bens de capital (EP4), o que indica que os países da Aladi não são exportadores relevantes dessas mercadorias, relativamente aos demais países da amostra. Em outras palavras, os países que fazem parte da Aladi não se caracterizam como uma região de intensa troca de partes, componentes e bens de capital que atestariam um elevado grau de integração produtiva. Esse é o caso dos países asiáticos e norte-americanos - os

(31) Vale dizer que a equação foi reestimada sem a variável de recursos naturais, a fim de verificar se os demais resultados e a capacidade explicativa do modelo se alteravam. Tal alteração não foi observada mostrando, por um lado, a robustez do modelo e, por outro, sugerindo que esse fator - ao menos da forma como foi representado - não tem uma influência muito forte nos fluxos de comércio. 
coeficientes do Asean e do Nafta para as referidas categorias (EP3 e EP4) são os mais elevados dentre os 8 acordos estudados.

Porém, é importante assinalar que, embora a integração produtiva aqui medida por meio dos fluxos de comércio seja baixa relativamente a outros acordos, as exportações intra-Aladi de partes, componentes e bens de capital são mais significativa do que as exportações dos países da Aladi para o resto do mundo. Isso fica claro na comparação dos coeficientes para EP3 e EP4 da dummy intrarregional daladi $(-0,779$ e $-0,945)$ com os coeficientes da dummy daladi-out, referente às exportações dos países da Aladi para o resto do mundo (-2,281 e -2,240). Em outras palavras, os países da Aladi não estão integrados nas cadeias globais de valor, porém, o grau de integração produtiva entre os países da região é menos débil.

Nesse sentido, vale chamar atenção para o fato de que o comércio intra-Aladi é sistematicamente superior ao extra-Aladi, independente da categoria de produtos.

Vale a pena enfatizar que os acordos com níveis mais elevados de integração produtiva - ou seja, com coeficientes significativos e positivos nas categorias de partes, componentes e bens de capital (EP3 e EP4) - são o Nafta, o Asean e a UE. No caso do Nafta, fica evidente a articulação da rede de montagem articulada entre os países: os coeficientes referentes ao comércio de partes, componentes e bens de capital são os mais elevados dentre os acordos e, ainda por cima, os coeficientes estimados para as demais categorias são negativos. No caso do Asean, apenas bens primários (EP1) têm um coeficiente não significativo, mas o comércio das categorias relevantes para a integração produtiva é muito mais elevado do que das demais categorias. Por fim, na UE, a integração produtiva aparece como relevante, sobretudo no que se refere a partes e componentes. Dos demais grupos de países, os países que faziam parte da URSS são os únicos a mostrar maior integração, ainda que o acordo (CIS) não pareça estimular o comércio regional de partes e componentes.

A fim de testar a influência dos maiores subacordos regionais - Mercosul e Comunidade Andina - sobre o acordo da Aladi, desagregamos a dummy da Aladi em duas versões: a primeira, na qual isolamos o efeito do Mercosul, e a segunda, na qual isolamos o efeito do Mercosul e da Comunidade Andina. Os coeficientes estimados para as três versões da dummy da Aladi encontram-se no Gráfico $5^{32}$.

A diferença mais significativa entre os coeficientes é para os bens primários. Quando estimamos a Aladi como um todo o coeficiente era 1,92, após a exclusão dos membros do Mercosul o coeficiente caiu para 0,85 , o que revela a importância

(32) As estimações com as diferentes versões da dummy daladi encontram-se no Anexo. 
do acordo do Mercosul ${ }^{33}$ para estes bens. Com a exclusão da Comunidade Andina o coeficiente apresentou um ligeiro aumento de 0,95 , revelando um impacto negativo deste bloco comercial para a Associação nesses produtos.

Para os demais setores, as variações não foram significativas. Para os bens intermediários de partes e componentes e bens finais de capital, os coeficientes da Aladi já eram negativos e tiveram seus valores intensificados após a exclusão do Mercosul, o que revela que os fluxos de exportação destes bens dentro do Mercosul são superiores às exportações destes bens na Aladi como um todo. De modo geral, observamos que o Mercosul impacta de forma mais intensa a Associação do que a Comunidade Andina, como era de se esperar por conta do tamanho dos países partícipes de cada um dos acordos e da intensidade de comércio entre eles.

Gráfico 5

Coeficientes das dummies da Aladi, Aladi sem Mercosul e Aladi sem Mercosul e Comunidade Andina por estágio de produção

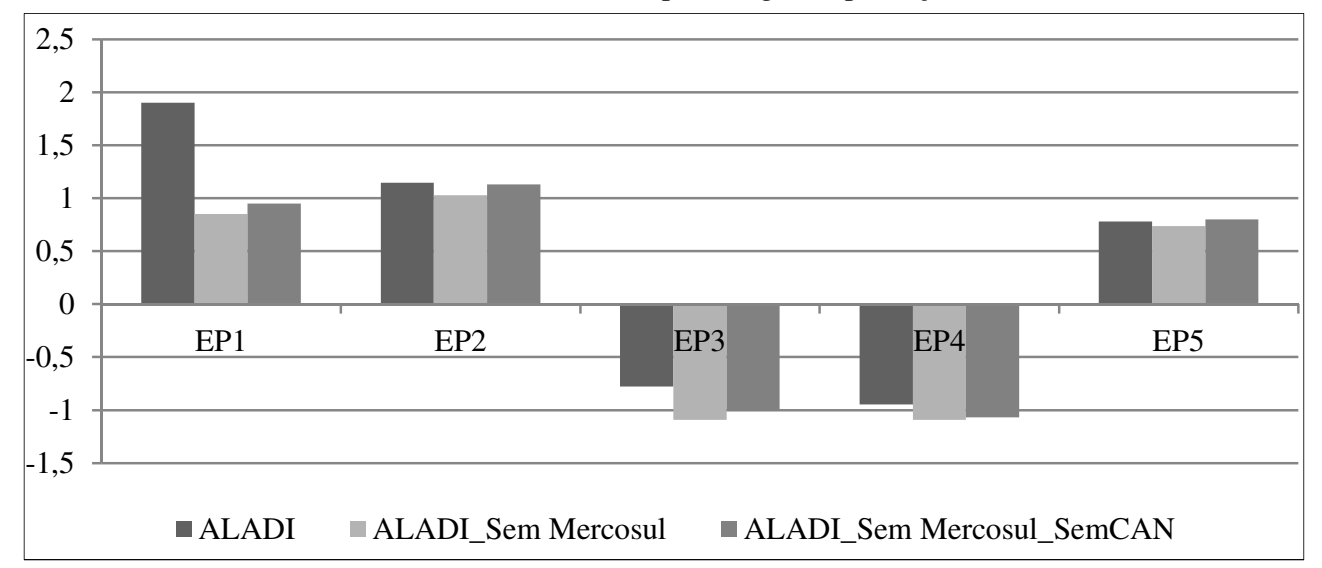

Diversos artigos usam a equação gravitacional para avaliar o processo de fragmentação via impacto do comércio de partes e componentes. Estes estudos corroboram a adequação da metodologia e encontram semelhanças nos coeficientes das variáveis gravitacionais. Poucos deles, no entanto, avaliam a influência dos acordos comerciais sobre o comércio desagregado. Kimura e Ando (2005) utilizam a equação gravitacional e estimam os determinantes das exportações de partes e componentes e bens finais; entretanto, os autores não utilizam a equação para estudar os fluxos intrabloco (não consideram a dimensão regional), pois seu principal objetivo consistia em testar a influência das diferenças de renda per capita sobre a fragmentação captada pelos fluxos bilaterais de partes e componentes. Lee, Park e Wang (2011) utilizaram a equação gravitacional para avaliar a diferença de

(33) A dummy que representa o acordo do Mercosul apresentou coeficiente igual a 3.85 para bens primários. 
intensidade do comércio de partes e componentes com diversos parceiros comerciais relativamente ao comércio dos demais bens. $\mathrm{O}$ único trabalho, a nosso conhecimento, a utilizar a equação gravitacional para relacionar acordos comerciais com fragmentação produtiva foi Orefice e Rocha (2014), que testa a "profundidade" dos acordos sobre os fluxos comerciais associados às redes globais de comércio e produção. Eles concluíram que a profundidade do acordo impacta diferentemente segundo os setores, sendo mais notável no caso de peças de automóveis e produtos de tecnologia e informação.

Desta forma, podemos concluir que, embora não haja na literatura estimações da equação gravitacional para verificar o impacto das Associações existentes na América Latina sobre os fluxos comerciais de partes e componentes, diversos artigos utilizaram metodologias semelhantes para outros acordos comerciais. Nestes trabalhos, a metodologia mostrou-se um bom indicador e revelou que, em sua maioria, os fluxos de partes e componentes são mais intensos no comércio intrarregional.

\section{Conclusões}

O cenário comercial e produtivo mundial tem sido marcado nas últimas duas décadas pelo aprofundamento do processo de fragmentação da produção. Este fenômeno, que levou à reorganização da produção em nível mundial, é caracterizado, no âmbito comercial, pelo aumento dos fluxos internacionais de serviços e bens, especialmente de produtos que participam de diferentes etapas do processo produtivo, como peças, componentes e bens finais de capital. A redução dos diversos tipos de custo - transporte, coordenação e outros - é fundamental para a organização das cadeias produtivas globais. Nesse sentido, os acordos comerciais são de particular importância, na medida em que eles contribuem para a redução dos custos de comércio e de transação de forma mais geral.

No caso da Aladi, o objetivo de integração e articulação das indústrias nacionais não estava presente na formulação dos acordos de Montevidéu (1980), mas a integração produtiva já foi evocada em diferentes contextos e sob diferentes formas ao longo das diversas fases pela qual passou o processo de integração latinoamericana desde os anos 60. Nesse contexto, esse artigo buscou analisar o grau de integração produtiva dos países da região - denominada aqui de articulação produtiva em virtude do baixo nível perante outros grupos de países - e, em seguida, examinar em que medida os acordos comerciais existentes da Aladi contribuíram para tal configuração.

A análise dos dados de comércio evidencia a baixa inserção dos países da Aladi nas cadeias globais de valor. Os dados referentes ao comércio total desses países revelam que essa fraca inserção se caracteriza por uma importância maior de 
partes, componentes e bens de capital nas importações da Aladi do que em suas exportações. Além disso, parte relevante dessas importações é proveniente de outras regiões do globo (notadamente, Ásia e EUA). Ou seja, a indústria regional, ao fabricar os produtos finais (vendidos em grande parte para a região, inclusive para os próprios mercados) com elevado conteúdo de bens intermediários provenientes de outras regiões, reforça a percepção de que os países da Aladi têm uma inserção pouco dinâmica nas redes globais de comércio e produção.

Ainda assim, no comércio intrarregional, as exportações de partes, componentes e bens de capital têm importância ligeiramente maior e, no lado das importações, seu peso é bem inferior ao observado nas importações totais. A composição da pauta exportadora da Aladi para o resto do mundo é bem diferente daquela observada entre os países do acordo, mostrando inclusive um maior grau de sofisticação dos bens transacionados, mas não mostra particular importância no que se refere aos bens característicos de uma maior integração produtiva. Ou seja, não somente os países da Aladi apresentam certo caráter "montador" de bens finais, mas sua demanda por bens localizados a jusante nas cadeias produtivas são provenientes majoritariamente de outras regiões, sem gerar efeitos multiplicadores no restante da região por meio da demanda de bens intermediários e de capital.

A estimação do modelo gravitacional, além de mostrar a diferença da influência dos determinantes dos fluxos de comércio para as cinco categorias de produtos, deixa evidente três aspectos relevantes acerca da questão da integração regional. Em primeiro lugar, o comércio intrarregional é sistematicamente mais intenso do que o comércio com terceiros países sinalizando para um efeito positivo dos acordos, visto que as demais características relacionadas ao tamanho das economias e à proximidade geográfica e cultural já estão controladas na equação gravitacional. Nesse sentido, a Aladi mostraria efeitos positivos em termos de intensificação do comércio intrarregional. Em segundo lugar, essa integração, no entanto, não tem uma conotação "produtiva" acentuada. Os coeficientes estimados para os bens passíveis de caracterizar uma integração entre as indústrias dos países da Aladi - partes, componentes e bens de capital - são bem inferiores àqueles observados nos três grupos de países onde esse fenômeno se mostra relevante Nafta, Asean e UE. Em terceiro lugar, os coeficientes estimados para o comércio de partes, componentes e bens de capital intra-Aladi, embora negativos, são superiores àqueles estimados para o comércio da Aladi com o resto do mundo. Isso significa que, apesar da baixa integração produtiva regional, ela é relativamente maior - ou menos fraca - no comércio intrarregional do que com resto do mundo.

Os benefícios da formação de redes produtivas regionais são reconhecidos nas análises acerca da inserção internacional dos países, sobretudo aquelas que têm como objeto a integração produtiva asiática. Esses benefícios estão geralmente associados à constatação de que a integração produtiva é capaz de distribuir de forma mais 
equitativa os ganhos da integração, sobretudo para os pequenos países. No caso da América Latina, a constatação da baixa integração produtiva e a persistente insatisfação dos pequenos países com a integração regional sugere que esse tema necessita ainda ser aprofundado, pensando-se nas especificidades da estrutura produtiva da região e nos instrumentos de política que devem ser utilizados para incentivá-la. Por fim, tal discussão deve ser conduzida, de um lado, sem considerar a integração dos países nas cadeias globais como uma panaceia e, de outro, levandose em conta o fato que uma maior integração produtiva regional pode implicar em alterações importantes nas relações comerciais entre os países da região.

\section{Referências bibliográficas}

ANDERSON, J. A theoretical foundation for the gravity equation. American Economic Review, v. 69, n. 1, p. 106-116, 1979.

; VAN WINCOOP, E. Gravity with gravitas: a solution to the border puzzle. American Economic Review, 93, p. 170-192, 2003.

The gravity model. NBER, Dec. 2010. (Working Paper Series, v. 16576).

ASSOCIAÇÃO LATINO-AMERICANA DE INTEGRAÇÃO (ALADI). II Tratado de Montevidéu - Instrumento que institui a Associação Latino-Americana de Integração (Aladi). Montevidéu: ago. 1980.

AZEVEDO, A. O efeito do Mercosul sobre o comércio: uma análise com o modelo gravitacional. Pesquisa e Planejamento Econômico, v. 34, n. 2, p. 307-309, 2004.

BALDWIN, R.; TAGLIONI, D. Gravity chains: estimating bilateral trade flows when parts and components trade is important. National Bureau of Economic Research, 2011. (NBER Working Papers, 16672).

BARCELLOS, P. Impactos comerciais da área de livre comércio das Américas: uma aplicação do modelo gravitacional. 2002. 98f. Dissertação (Mestrado em Economia)- niversidade Federal do Rio Grande do Sul, Porto Alegre, 2002.

BAUMANN, R. Regional trade and growth in Asia and Latin America: the importance of productive complementarity. Brasília: Cepal, 2010.

BRAGA, M. Integração econômica regional na América Latina: uma interpretação das contribuições da Cepal. In: ENCONTRO NACIONAL DE ECONOMIA, 29, 2001, Salvador, BA, 2001. Anais...

CASTILHO, M. Protection et accès au marché européen: le cas du Mercosur. 1999. Thèse de doctorat-Université de Paris I, Panthéon Sorbonne, Paris, 1999.

Acesso das exportações do Mercosul ao mercado norte-americano. Rio de Janeiro: Ipea, 2001. (Texto para Discussão, n. 851). 
CEPAL. Open regionalism in Latin America and the Caribbean. Santiago do Chile, 1994.

- Panorama de la inserción internacional de América Latina y el Caribe: crisis duradera en el centro y nuevas oportunidades para las economías en desarrollo. Santiago do Chile: Naciones Unidas, 2012. 177p.

Comercio internacional y desarrollo inclusivo: construyendo sinergias. Santiago do Chile: Naciones Unidas, abr. 2013. 210p.

CHENG, H.; HOWARD, W. Controlling for heterogeneity in gravity models of trade and integration review. Federal Reserve Bank of St. Louis, 2005. (Working Paper, 1999-010E).

CHUDNOVSKY, D.; CAMPBELL, G. Argentina-Brasil: luces y sombras. Texto preparado para o $27^{\circ}$ Colóquio de IDEA. Buenos Aires: Instituto para El Desarrollo de Empresários em la Argentina, 1991.

DEARDORFF, A. Fragmentation in simple trade models. North American Journal of Economics and Finance, 12, p. 12-37, 2001.

DULLIEN, S. Integração produtiva na União Europeia: uma perspectiva alemã. In: INTEGRAÇÃO produtiva - caminhos para o Mercosul. Brasília, 2010. (Série Cadernos da Indústria ABDI, v. XVI).

EVENETT, S.; KELLER, W. On theories explaining the success of the gravity equation. Journal of Political Economy, v. 110, n. 21, 2002.

GOMEZ HERRERA, E. Comparing alternative methods to estimate gravity models of bilateral trade. Department of Economic Theory and Economic History of the University of Granada, 2010.

; BALEIX, J. Are estimation techniques neutral to estimate gravity equations? An application to the impact of EMU on third countries' exports. Trabalho apresentado na ETSG. Roma, 2009. Disponível em http://www.etsg.org /ETSG2009/ETSG2009Programme.html.

HAMAGUCHI, N. Integração produtiva regional no leste da Ásia. In: INTEGRAÇÃO Produtiva - caminhos para o Mercosul. Brasília, 2010. (Série Cadernos da Indústria ABDI, v. XVI).

HEAD, K.; MAYER, T. Gravity equations: workhorse, Toolkit, and Cookbook. In: GOPINATH, G.; HELPMAN, E.; ROGOFF, K. (Ed.). Handbook of international economics. Elsevier, 2014. v. 4, p. 131-195.

(2000). Gravity for beginners. Disponível em: http://www.unescap.org/ tid/artnet/mtg/gravity10.asp. Acesso em: 27 set. 2010.

HELPMAN, E. Understanding global trade. Harvard College, 2011. 
HUMMELS, D.; RAPOPORT, D.; YI, K. Vertical specialization and the changing nature of world trade. Economic Policy Review, Federal Reserve Bank of New York, issue Jun., p. 79-99, 1998

JONES, R.; KIERZKOWSKI, H. The role of services in production and internacional trade: a theorical framework. In: JONES, R.; KRUEGER, A. (Ed.). The political economy of international trade. Oxford: Blackwell's, 1990. p. 31-48.

JORGE, C.; CASTILHO, M. Impacto da integração regional sobre os fluxos mundiais de Investimento Direto Estrangeiro. Economia e Sociedade, Campinas, IE/Unicamp, n. 42, 2011.

KIMURA, F., TAKAHASHI, Y. e HAYAKAWA, K. Fragmentation and parts and components trade: comparison between East Asia and Europe. North American Journal of Economics and Finance, v. 18, n. 1, p. 23-40, 2007.

; ANDO, M. Two-dimensional fragmentation in East Asia: conceptual framework and empirical. International Review of Economics and Finance, n. 17, 2005.

KOSACOFF, B.; LÓPEZ, A. América Latina y las cadenas globales de valor: debilidades y pontecialidades. Revista Globalización, Competititividad y Gobernabilidad, Georgetown University, v. 2, n. 1, 2008.

LEE, H.; PARK, D.; WANG, J. The role of the people's Republic of China in international fragmentation and production networks: an empirical investigation. Asian Development Bank, 2011. (ADB Working Paper Series on Regional Economic Integration, n. 87).

LEMOINE, F.; UNAL-KESENCI, D. China in the international segmentation of production processes. Paris: CEPII, 2002. (Document de Travail du CEPII, 200202).

LINDERS, G.; GROOT, H. Estimation of the gravity equation in the presence of zero flow. Tinbergen Institute, 2006. (Discussion Paper TI, 2006-072/3).

LINNEMANN, H. An econometric study of international trade flows. Amsterdam: NorthHolland, 1966.

MACADAR, B. O Incentivo à cadeia produtiva regional como estratégia para o aprofundamento do Mercosul. Indicadores Econômicos FEE, v. 38, n. 2. p. 27-34, 2010.

MACHADO, J. Integração produtiva: referencial analítico, experiência europeia e lições para o Mercosul. In: INTEGRAÇÃO Produtiva - caminhos para o Mercosul. Brasília, 2010. (Série Cadernos da Indústria ABDI, v. XVI). 
MEDEIROS, C. Integração produtiva: a experiência asiática e algumas referências para o Mercosul. In: INTEGRAÇÃO Produtiva - caminhos para o Mercosul. (Série Cadernos da Indústria ABDI, v. XVI). Brasília, 2010.

MIROUDOT, S.; RAGOUSSIS, A. Vertical trade, trade costs and FDI. Jul. 2009. (OCDE Trade Policy Working Papers, n. 89).

MOTTA VEIGA, P. RIOS, S. Cadeias de Valor baseadas em recursos naturais e upgrading de empresas e setores: o caso da América do Sul. Rio de Janeiro: Cindes, 2008. (Breves Cindes, n. 9).

PAIVA, D.; BRAGA, M. Integração econômica regional e desenvolvimento econômico: reflexões sobre a experiência latino-americana. Revista de Desenvolvimento Econômico, Ano IX, n. 16, dec. 2007.

PEREZ, C. Una visión para América Latina: dinamismo tecnológico e inclusión social mediante una estrategia basada en los recursos naturales. Revista Econômica, Niterói, v. 14, n. 2, p. 11-54, dez. 2012.

OREFICE, G.; ROCHA, N. Deep integration and production networks: an empirical analysis. The World Economy, v. 37, n. 1, p. 106-136, 2014.

REIS, M.; AZEVEDO, A. O impacto da criação do Mercosul no fluxo de comércio bilateral: uma abordagem com o modelo gravitacional. In: ENCONTRO NACIONAL DE ECONOMIA, 36, ANPEC - Associação Nacional dos Centros de Pós graduação em Economia, 2008. Anais...

SOUZA, K. Integração comercial e produtiva na América Latina: o caso da Aladi. 2005. Tese (Doutorado em Economia)-Universidade Federal Fluminense, Niterói, 2005 .

STURGEON, T. Global value chains and economic globalization: towards a measurement framework. A report to Eurostat. 2013. _Disponível em: file:///C:/Users/Karla/Downloads/Sturgeon_report_Eurostat.pdf. 


\section{Anexo}

Tabela A.1

Estatísticas da amostra da estimação da equação gravitacional

\begin{tabular}{l|c|c|c|c|c}
\hline Variáveis & $\mathrm{N}^{\circ}$ Obs & Média & $\begin{array}{c}\text { Desvio } \\
\text { Padrão }\end{array}$ & Mínimo & Máximo \\
\hline Exportações & 265320 & $313,809.90$ & 1999806.0 & - & $119,000,000.00$ \\
\hline Distância & 265320 & $7,168.10$ & 5017.8 & 59.62 & $19,772.34$ \\
\hline PIB_cte_exp & 265320 & $636,035.90$ & 1667385.0 & $2,043.00$ & $13,300,000.00$ \\
\hline PIB_cte_imp & 265320 & $636,035.90$ & 1667385.0 & $2,043.00$ & $13,300,000.00$ \\
\hline GAP (PIB_percapita_cte) & 265320 & - & 1.9 & -4.98 & 4.98 \\
\hline Recursos naturais & 265320 & 0.23 & 0.1 & 0.05 & 0.76 \\
\hline
\end{tabular}

Tabela A.2

Estimação (Painel em Poisson) da Equação Gravitacional para ALADI sem Mercosul (var. dependente: exportações)

\begin{tabular}{|c|c|c|c|c|c|c|}
\hline Variáveis & Total & EP1 & $\mathrm{EP} 2$ & EP3 & EP4 & EP5 \\
\hline \multirow{2}{*}{ Log (pib_cte_exp) } & $1.432 * * *$ & $1.029 * * *$ & $1.258 * * *$ & $0.801 * * *$ & $1.307 * * *$ & $0.902 * * *$ \\
\hline & $(0.000)$ & $(0.000)$ & $(0.000)$ & $(0.000)$ & $(0.000)$ & $(0.000)$ \\
\hline \multirow{2}{*}{ Log (pib_cte_imp) } & $1.624 * * *$ & $1.716^{* * * *}$ & $0.690 * * *$ & $0.333 * * *$ & $0.309 * * *$ & $0.908 * * *$ \\
\hline & $(0.000)$ & $(0.000)$ & $(0.000)$ & $(0.000)$ & $(0.000)$ & $(0.000)$ \\
\hline \multirow{2}{*}{$\begin{array}{l}\text { Log } \\
\text { (gap_pib_cte_capita) }\end{array}$} & $0.0679 * * *$ & $0.153^{* * *}$ & $0.0395 * * *$ & $0.0826 * * *$ & $0.0362 * * *$ & $0.0519 * * *$ \\
\hline & $(0.000)$ & $(0.000)$ & $(0.000)$ & $(0.000)$ & $(0.000)$ & $(0.000)$ \\
\hline \multirow{2}{*}{ Distância } & $-1.533 * * *$ & $-1.326 * * *$ & $-1.109 * * *$ & $-0.208 * * *$ & $-0.531 * * *$ & $-0.884 * * *$ \\
\hline & $(0.036)$ & $(0.057)$ & $(0.031)$ & $(0.044)$ & $(0.035)$ & $(0.028)$ \\
\hline \multirow{2}{*}{ Contiguidade } & $0.891 * * *$ & $1.512 * * *$ & $0.744 * * *$ & $0.873 * * *$ & $0.883 * * *$ & $1.266 * * *$ \\
\hline & $(0.155)$ & $(0.218)$ & $(0.143)$ & $(0.206)$ & $(0.173)$ & $(0.135)$ \\
\hline \multirow{2}{*}{ Colônia } & $-1.187 * * *$ & $-0.932 * * *$ & 0.116 & $0.400 *$ & $0.493 * *$ & 0.198 \\
\hline & $(0.182)$ & $(0.248)$ & $(0.168)$ & $(0.226)$ & $(0.194)$ & $(0.167)$ \\
\hline \multirow{2}{*}{ Língua comum } & 0.0534 & -0.114 & $0.705 * * *$ & $1.142 * * *$ & $1.021 * * *$ & $0.735 * * *$ \\
\hline & $(0.143)$ & $(0.190)$ & $(0.127)$ & $(0.143)$ & $(0.129)$ & $(0.125)$ \\
\hline \multirow{2}{*}{$\begin{array}{l}\text { Log (recursos } \\
\text { naturais) }\end{array}$} & $-0.0429 * * *$ & $0.203 * * *$ & $-0.00815^{* * *}$ & $0.0793 * * *$ & $-0.000754 * * *$ & $-0.0939 * * *$ \\
\hline & $(0.000)$ & $(0.000)$ & $(0.000)$ & $(0.000)$ & $(0.000)$ & $(0.000)$ \\
\hline \multirow{2}{*}{$\begin{array}{l}\text { Dummy } \\
\text { Aladi_smercosul }\end{array}$} & $0.950 * * *$ & $0.849 * * *$ & $1.027 * * *$ & $-1.092 * * *$ & $-1.092 * * *$ & $0.738 * * *$ \\
\hline & $(0.231)$ & $(0.307)$ & $(0.206)$ & $(0.243)$ & $(0.221)$ & $(0.206)$ \\
\hline \multirow{2}{*}{ Dummy Mercosul } & $2.781 * * *$ & $3.852 * * *$ & $1.775 * * *$ & 0.612 & -0.154 & $1.059 * *$ \\
\hline & $(0.534)$ & $(0.720)$ & $(0.497)$ & $(0.684)$ & $(0.572)$ & $(0.496)$ \\
\hline \multirow{2}{*}{ Dummy Não Aladi } & $0.339 * * *$ & $0.820 * * *$ & $0.946 * * *$ & $-2.280 * * *$ & $-2.239 * * *$ & 0.0513 \\
\hline & $(0.082)$ & $(0.114)$ & $(0.079)$ & $(0.104)$ & $(0.087)$ & $(0.0768)$ \\
\hline \multirow{2}{*}{ Dummy Asean } & $0.853 * * *$ & 0.461 & $1.249 * * *$ & $3.041 * * *$ & $2.094 * * *$ & $1.580 * * *$ \\
\hline & $(0.329)$ & $(0.441)$ & $(0.310)$ & $(0.421)$ & $(0.354)$ & $(0.309)$ \\
\hline \multirow{2}{*}{ Dummy Cefta } & $-0.594 * *$ & $-0.961 * *$ & $0.455^{*}$ & 0.22 & 0.229 & $0.665 * *$ \\
\hline & $(0.281)$ & $(0.383)$ & $(0.266)$ & $(0.364)$ & $(0.305)$ & $(0.265)$ \\
\hline
\end{tabular}


Karla Sarmento Gonçalves de Souza / Marta Reis Castilho

Tabela A.2 - Continuação

\begin{tabular}{l|c|c|c|c|c|c}
\hline Variáveis & Total & EP1 & EP2 & EP3 & EP4 & EP5 \\
\hline \multirow{2}{*}{ Dummy Cer } & -0.618 & -0.111 & 0.944 & 0.7 & 1.082 & 1.79 \\
\cline { 2 - 7 } & $(1.261)$ & $(1.695)$ & $(1.192)$ & $(1.609)$ & $(1.357)$ & $(1.192)$ \\
\hline \multirow{2}{*}{ Dummy Cis } & $3.231 * * *$ & $2.214 * * *$ & $1.646 * * *$ & 0.803 & $1.750 * * *$ & $2.234 * * *$ \\
\cline { 2 - 7 } & $(0.398)$ & $(0.546)$ & $(0.379)$ & $(0.526)$ & $(0.437)$ & $(0.376)$ \\
\hline \multirow{3}{*}{ Dummy EU Efta } & $-0.898 * * *$ & $-2.066 * * *$ & -0.0118 & $1.173 * * *$ & $0.994 * * *$ & $0.477 * * *$ \\
\cline { 2 - 7 } & $(0.121)$ & $(0.176)$ & $(0.104)$ & $(0.145)$ & $(0.121)$ & $(0.103)$ \\
\hline \multirow{2}{*}{ Dummy Nafta } & -0.854 & $-1.782 *$ & 0.877 & -0.845 & 0.0171 & 0.0924 \\
\hline \multirow{2}{*}{ Constante } & $(0.725)$ & $(0.975)$ & $(0.686)$ & $(0.927)$ & $(0.781)$ & $(0.685)$ \\
\hline & $-5.020 * * *$ & $-4.084 * * *$ & $-1.460 * *$ & $3.649 * * *$ & $3.324 * * *$ & -0.285 \\
\hline Observações & $(0.726)$ & $(0.973)$ & $(0.691)$ & $(0.945)$ & $(0.797)$ & $(0.689)$ \\
\hline No de pares de país & $1.143 * * *$ & $1.734 * * *$ & $-3.520 * * *$ & $-1.714 * * *$ & $1.293 * * *$ & $-4.223 * * *$ \\
\hline
\end{tabular}

Erro padrão robusto entre parênteses. Nota: $* * * \mathrm{p}<0.01, * * \mathrm{p}<0.05, * \mathrm{p}<0.1$

Tabela A.3

Estimação (Painel em Poisson) da Equação Gravitacional para Aladi sem Mercosul sem CAN (var. dep.: exportações)

\begin{tabular}{|c|c|c|c|c|c|c|}
\hline Variáveis & Total & EP1 & EP2 & EP3 & $\mathrm{EP} 4$ & EP5 \\
\hline \multirow{2}{*}{ Log (pib_cte_exp) } & $1.432 * * *$ & $1.029 * * *$ & $1.258 * * *$ & $0.801 * * *$ & $1.307 * * *$ & $0.902 * * *$ \\
\hline & $(0.000)$ & $(0.000)$ & $(0.000)$ & $(0.000)$ & $(0.000)$ & $(0.000)$ \\
\hline \multirow{2}{*}{ Log (pib_cte_imp) } & $1.624 * * *$ & $1.716^{* * * *}$ & $0.690 * * *$ & $0.333 * * *$ & $0.309 * * *$ & $0.908 * * *$ \\
\hline & $(0.000)$ & $(0.000)$ & $(0.000)$ & $(0.000)$ & $(0.000)$ & $(0.000)$ \\
\hline \multirow{2}{*}{$\begin{array}{l}\text { Log } \\
\text { (gap_pib_cte_capita) }\end{array}$} & $0.0679 * * *$ & $0.153^{* * * *}$ & $0.0395 * * *$ & $0.0826 * * *$ & $0.0362 * * *$ & $0.0519 * * *$ \\
\hline & $(0.000)$ & $(0.000)$ & $(0.000)$ & $(0.000)$ & $(0.000)$ & $(0.000)$ \\
\hline \multirow{2}{*}{ Distância } & $-1.534 * * *$ & $-1.327 * * *$ & $-1.109 * * *$ & $-0.211 * * *$ & $-0.532 * * *$ & $-0.884 * * *$ \\
\hline & $(0.036)$ & $(0.057)$ & $(0.031)$ & $(0.044)$ & $(0.035)$ & $(0.028)$ \\
\hline \multirow{2}{*}{ Contiguidade } & $0.895 * * *$ & $1.551 * * *$ & $0.766 * * *$ & $0.900 * * *$ & $0.884 * * *$ & $1.274 * * *$ \\
\hline & $(0.155)$ & $(0.221)$ & $(0.144)$ & $(0.209)$ & $(0.173)$ & $(0.136)$ \\
\hline \multirow{2}{*}{ Colônia } & $-1.188 * * *$ & $-0.941 * * *$ & 0.111 & $0.387^{*}$ & $0.491 * *$ & 0.196 \\
\hline & $(0.182)$ & $(0.248)$ & $(0.168)$ & $(0.226)$ & $(0.194)$ & $(0.167)$ \\
\hline \multirow{2}{*}{ Língua comum } & 0.0545 & -0.111 & $0.709 * * *$ & $1.165 * * *$ & $1.024 * * *$ & $0.739 * * *$ \\
\hline & $(0.143)$ & $(0.191)$ & $(0.127)$ & $(0.146)$ & $(0.130)$ & $(0.126)$ \\
\hline \multirow{2}{*}{$\begin{array}{l}\text { Log (Recursos } \\
\text { Naturais) }\end{array}$} & $-0.0429 * * *$ & $0.203 * * *$ & $-0.00815 * * *$ & $0.0793 * * *$ & $-0.000754 * * *$ & $-0.0939 * * *$ \\
\hline & $(0.000)$ & $(0.000)$ & $(0.000)$ & $(0.000)$ & $(0.000)$ & $(0.000)$ \\
\hline \multirow{2}{*}{ Dummy Mercosul } & $2.778 * * *$ & $3.849 * * *$ & $1.767 * * *$ & 0.582 & -0.156 & $1.053 * *$ \\
\hline & $(0.534)$ & $(0.720)$ & $(0.497)$ & $(0.685)$ & $(0.572)$ & $(0.496)$ \\
\hline \multirow{2}{*}{$\begin{array}{l}\text { Dummy } \\
\text { Aladi_smercosul_scan }\end{array}$} & $1.038 * * *$ & $0.949 * * *$ & $1.130 * * *$ & $-1.006 * * *$ & $-1.070 * * *$ & $0.801 * * *$ \\
\hline & $(0.244)$ & $(0.324)$ & $(0.219)$ & $(0.261)$ & $(0.234)$ & $(0.218)$ \\
\hline \multirow{2}{*}{ Dummy Can } & 0.275 & -0.122 & 0.118 & $-1.911 * * *$ & $-1.233 * *$ & 0.29 \\
\hline & $(0.469)$ & $(0.645)$ & $(0.442)$ & $(0.602)$ & $(0.502)$ & $(0.440)$ \\
\hline
\end{tabular}


Tabela A.3 - Continuação

\begin{tabular}{|c|c|c|c|c|c|c|}
\hline Variáveis & Total & EP1 & EP2 & EP3 & EP4 & EP5 \\
\hline \multirow{2}{*}{ Dummy Não Aladi } & $0.339 * * *$ & $0.821 * * *$ & $0.947 * * *$ & $-2.276^{* * *}$ & $-2.239 * * *$ & 0.0521 \\
\hline & $(0.082)$ & $(0.114)$ & $(0.079)$ & $(0.104)$ & $(0.087)$ & $(0.077)$ \\
\hline \multirow{2}{*}{ Dummy Asean } & $0.851 * * *$ & 0.455 & $1.245 * * *$ & $3.029 * * *$ & $2.093 * * *$ & $1.579 * * *$ \\
\hline & $(0.329)$ & $(0.441)$ & $(0.310)$ & $(0.421)$ & $(0.354)$ & $(0.309)$ \\
\hline \multirow{2}{*}{ Dummy Cefta } & $-0.596 * *$ & $-0.972 * *$ & $0.450 *$ & 0.207 & 0.227 & $0.663 * *$ \\
\hline & $(0.281)$ & $(0.383)$ & $(0.266)$ & $(0.364)$ & $(0.305)$ & $(0.265)$ \\
\hline \multirow{2}{*}{ Dummy Cer } & -0.62 & -0.114 & 0.94 & 0.676 & 1.078 & 1.782 \\
\hline & $(1.261)$ & (1.694) & $(1.192)$ & $(1.609)$ & $(1.357)$ & $(1.192)$ \\
\hline \multirow{2}{*}{ Dummy Cis } & $3.231 * * *$ & $2.212 * * *$ & $1.642 * * *$ & 0.791 & $1.749 * * *$ & $2.234 * * *$ \\
\hline & $(0.398)$ & $(0.546)$ & $(0.378)$ & $(0.526)$ & $(0.437)$ & $(0.376)$ \\
\hline \multirow{2}{*}{ Dummy EU } & $-0.901 * * *$ & $-2.077 * * *$ & -0.0147 & $1.166^{* * *}$ & $0.993 * * *$ & $0.475^{* * *}$ \\
\hline & $(0.121)$ & $(0.176)$ & $(0.104)$ & $(0.145)$ & $(0.121)$ & $(0.103)$ \\
\hline \multirow{2}{*}{ Dummy Efta } & -0.855 & $-1.782 *$ & 0.878 & -0.846 & 0.0166 & 0.0921 \\
\hline & $(0.725)$ & $(0.975)$ & $(0.685)$ & $(0.927)$ & $(0.781)$ & $(0.685)$ \\
\hline \multirow{2}{*}{ Dummy Nafta } & $-5.022 * * *$ & $-4.091 * * *$ & $-1.475 * *$ & $3.622 * * *$ & $3.322 * * *$ & -0.29 \\
\hline & $(0.725)$ & $(0.973)$ & $(0.691)$ & $(0.946)$ & $(0.797)$ & $(0.689)$ \\
\hline \multirow{2}{*}{ Constante } & $1.143 * * *$ & $1.734 * * *$ & $1.033 * * *$ & $-1.690 * * *$ & $1.293 * * *$ & $-4.219 * * *$ \\
\hline & $(0.017)$ & $(0.017)$ & $(0.018)$ & $(0.384)$ & $(0.018)$ & $(0.243)$ \\
\hline Observações & 265,320 & 53,064 & 53,064 & 53,064 & 53,064 & 53,064 \\
\hline $\mathrm{N}^{\circ}$ de pares de país & 4,422 & 4,422 & 4,422 & 4,422 & 4,422 & 4,422 \\
\hline
\end{tabular}

Erro padrão robusto entre parênteses. Nota: $* * * \mathrm{p}<0.01, * * \mathrm{p}<0.05, * \mathrm{p}<0.1$.

Quadro A.1

Correspondência entre a classificação BEC e estágio de produção

\begin{tabular}{|l|c|l|}
\hline \multirow{2}{*}{ Estágio de Produção } & $\begin{array}{c}\text { Código } \\
\text { BEC }\end{array}$ & $\begin{array}{l}\text { Nome } \\
\text { BEC }\end{array}$ \\
\hline \multirow{2}{*}{ Bens primários } & 111 & $\begin{array}{l}\text { Alimentos e bebidas básicos destinados principalmente à } \\
\text { indústria }\end{array}$ \\
\cline { 2 - 3 } & 21 & Insumos industriais básicos, não especificados \\
\cline { 2 - 3 } & 31 & Combustíveis e lubrificantes próprios \\
\hline \multirow{3}{*}{$\begin{array}{l}\text { Bens intermediários - } \\
\text { Semiacabados }\end{array}$} & 121 & $\begin{array}{l}\text { Alimentos e bebidas processadas destinados principalmente a } \\
\text { indústria }\end{array}$ \\
\cline { 2 - 3 } & 22 & Insumos industriais processados, não especificados \\
\cline { 2 - 3 } & 32 & Combustíveis e lubrificantes processados \\
\hline \multirow{2}{*}{$\begin{array}{l}\text { Bens intermediários }- \\
\text { Partes e componente }\end{array}$} & 42 & $\begin{array}{l}\text { Peças e acessórios de bens de capital - exceto material de } \\
\text { transporte }\end{array}$ \\
\cline { 2 - 3 } & 53 & Peças e acessórios de material de transporte \\
\hline \multirow{2}{*}{$\begin{array}{l}\text { Bens finais - Bens de } \\
\text { Capital }\end{array}$} & 41 & Bens de capital - exceto material de transporte \\
\cline { 2 - 3 } & 521 & $\begin{array}{l}\text { Material de transporte, peças e acessórios: outros, destinados à } \\
\text { indústria }\end{array}$ \\
\hline
\end{tabular}

Continua... 
Quadro A.1 - Continuação

\begin{tabular}{|l|c|l|}
\hline \multirow{7}{*}{$\begin{array}{l}\text { Bens finais - Bens de } \\
\text { Consumo }\end{array}$} & 112 & $\begin{array}{l}\text { Alimentos e bebidas básicos destinados principalmente para } \\
\text { consumo doméstico }\end{array}$ \\
\cline { 2 - 3 } & 122 & $\begin{array}{l}\text { Alimentos e bebidas processados destinados principalmente } \\
\text { para consumo doméstico }\end{array}$ \\
\cline { 2 - 3 } & 51 & $\begin{array}{l}\text { Material de transporte, peças e acessórios: veículos automotores } \\
\text { de passageiros }\end{array}$ \\
\cline { 2 - 3 } & 522 & $\begin{array}{l}\text { Material de transporte, peças e acessórios: outros, não } \\
\text { destinados à indústria }\end{array}$ \\
\cline { 2 - 3 } & 61 & Bens de consumo duráveis não especificados \\
\cline { 2 - 3 } & 62 & Bens de consumo semiduráveis não especificados \\
\cline { 2 - 3 } & 63 & Bens de consumo não duráveis não especificados \\
\hline
\end{tabular}

Fonte: Lemoine e Unal-Kesenci (2002)

Quadro A.2

Lista de países da base de dados

\begin{tabular}{|l|l|l|l|}
\hline Albânia & Croata & Irlanda & Polônia \\
Alemanha & República Tcheca & Islândia & Portugal \\
Argélia & Dinamarca & Itália & Quirquistão \\
Austrália & Egito & Japão & Reino Unido \\
Áustria & Equador & Cazaquistão & República Eslovaca \\
Belarus & Eslovênia & Látvia & Romênia \\
Bolívia & Espanha & Lituânia & Rússia \\
Bósnia e Herzegovina & Estados Unidos & Macedônia & Singapura \\
Brasil & Estônia & Malásia & Suécia \\
Brunei & Filipinas & Marrocos & Suíça \\
Bulgária & Finlândia & México & Tailândia \\
Canadá & França & Nigéria & Tunísia \\
Chile & Gabão & Noruega & Turquia \\
China & Holanda & Nova Zelândia & Ucrânia \\
Colômbia & Hungria & Paquistão & Uruguai \\
Coréia & Índia & Paraguai & Venezuela \\
\hline
\end{tabular}

Quadro A.3

Lista dos Acordos Preferenciais de comércio

\begin{tabular}{|l|l|l|}
\hline \multirow{3}{*}{ Aladi } & $\begin{array}{l}\text { Associação Latino- } \\
\text { Americana de } \\
\text { Integração }\end{array}$ & $\begin{array}{l}\text { Argentina (1980), Brasil (1980), Bolívia (1980), Colômbia } \\
(1980), \text { Equador (1980), México (1980), Paraguai (1980), } \\
\text { Peru (1980), Uruguai (1980), Venezuela (1980). }\end{array}$ \\
\hline \multirow{3}{*}{ Asean } & $\begin{array}{l}\text { Associação das Nações } \\
\text { do Sudeste Asiático }\end{array}$ & $\begin{array}{l}\text { Laos (1984), Camboja (1999), Indonésia (1967), } \\
(1967), \text { Cingapura (1967), Tailândia (1967), Vietnam } \\
(1995) .\end{array}$ \\
\hline
\end{tabular}

Continua... 
Quadro A.3 - Continuação

\begin{tabular}{|c|c|c|}
\hline CAN & Comunidade Andina & $\begin{array}{l}\text { Bolívia (1969), Colômbia (1969), Equador (1969), } \\
\text { Peru (1969), Venezuela (1973). }\end{array}$ \\
\hline CEFTA & $\begin{array}{l}\text { Acordo de Livre } \\
\text { Comércio da Europa } \\
\text { Central }\end{array}$ & $\begin{array}{l}\text { Bulgária (1998), Croácia (2002) e România (1997) / } \\
\text { Polônia (1992-2004), Hungria (1992-2002), República } \\
\text { Tcheca (1992-2004), Eslováquia (1992-2004), Eslovênia } \\
\text { (1996-2004). Obs. * República Tcheca e Eslováquia } \\
\text { participaram durante certo período como Tchecoslováquia }\end{array}$ \\
\hline CER & $\begin{array}{l}\text { Closer Economic } \\
\text { Relations* }\end{array}$ & Austrália (1983) e Nova Zelândia (1983). \\
\hline CIS & $\begin{array}{l}\text { Nação dos Estados } \\
\text { Independentes }\end{array}$ & $\begin{array}{l}\text { Azerbaijão (1991), Armênia (1991), Belarus (1991), } \\
\text { Geórgia (1993) Moldávia (1991), Cazaquistão (1991), } \\
\text { Rússia (1991), Ucrânia (1991), Uzbequistão (1991), } \\
\text { Tadjiquistão (1991), República do Quirquistão (1991). }\end{array}$ \\
\hline $\mathrm{EC}$ & Comunidade Europeia & $\begin{array}{l}\text { Áustria (1995), Bélgica (1952), Chipre (1994), República } \\
\text { Tcheca (1994), Dinamarca (1973), Estônia (1994), } \\
\text { Finlândia (1995), França (1952), Alemanha (1952), Grécia } \\
\text { (1981), Hungria (1994), Irlanda (1973), Itália (1952), } \\
\text { Letônia (1994), Lituânia (1994), Luxemburgo (1952), } \\
\text { Malta (1994), Holanda (1952), Polônia (1994), Portugal } \\
\text { (1986), República Eslovaca (1994), Eslovênia (1994), } \\
\text { Espanha (1986), Suécia (1995) e Reino Unido (1973). }\end{array}$ \\
\hline EFTA & $\begin{array}{l}\text { Associação Europeia } \\
\text { de Livre Comércio }\end{array}$ & $\begin{array}{l}\text { Islândia (2002), Liechtenstein (2002), Noruega (2002) e } \\
\text { Suíça (2002). }\end{array}$ \\
\hline MERCOSUL & $\begin{array}{l}\text { Mercado Comum do } \\
\text { Sul }\end{array}$ & $\begin{array}{l}\text { Argentina (1991), Brasil (1991), Paraguai (1991) e } \\
\text { Uruguai (1991) }\end{array}$ \\
\hline NAFTA & $\begin{array}{l}\text { Acordo Norte- } \\
\text { Americano de Livre } \\
\text { Comércio }\end{array}$ & Canadá (1994), México (1994) e Estados Unidos (1994). \\
\hline
\end{tabular}

Fonte: OMC. 